\title{
SITUAÇÃO DIDÁTICA OLÍMPICA (SDO): Aplicações da Teoria das Situações Didáticas para o Ensino de Olimpíadas
}

\author{
Francisco Regis Vieira Alves ${ }^{1}$
}

\begin{abstract}
RESUMO
De modo particular, o contexto de ensino de Matemática, cujo foco e interesse maior orienta-se para o âmbito de competições olímpicas, não pode desconsiderar e prescindir de um expediente de análise e apreciação apurada, sobretudo quando direcionamos o olhar para a ação específica do professor. Dessa forma, no presente trabalho encontramos uma proposta, com certo teor de ineditismo, que busca balizar a noção de Situação Didática Olímpica - SDO - a partir de uma metodologia de ensino oriunda da vertente francófona da Didática da Matemática, conhecida como Teoria das Situações Didáticas - TSD. Assim, este escrito pretende extrair algumas noções e aspectos imprescindíveis das fases dialéticas para o ensino, com o escopo de promover um cenário de aprendizagem capaz de incluir e "seduzir" estudantes não competidores. Para exemplificar, o trabalho aborda dois exemplos de Problemas Olímpicos - PO - que, originalmente, inseridos em um sistema de avaliação e de "classificação" de estudantes com habilidades reconhecidamente diferenciadas, mas, todavia, a partir dos pressupostos da TSD e da inclusão da tecnologia, são estruturados e descritos com o escopo de incentivar a mobilização de raciocínios diferenciados e apoiados em heurísticas e estratégias que, de modo geral, permanecem restritos aos contexto de preparação oficial específica para a competição matemática olímpica.
\end{abstract}

Palavras-chave: Situação Didática Olímpica. Olimpíadas de Matemática. Ensino. Tecnologia.

OLYMPIC DIDACTIC SITUATION (ODS):

APPLICATIONS OF THE THEORY OF DIDACTIC SITUATIONS FOR TEACHING THE OLYMPICS

\begin{abstract}
In a particular way, the context of Mathematics teaching, whose focus and greater interest is oriented to the scope of Olympic competitions, cannot disregard and dispense with an expedient analysis and appreciation, especially when we direct the look for the specific action of the teacher. Thus, in the present work, we find a proposal, with a certain content of novelty, which seeks to describe the notion of Olympic Didactic Situation - ODS -, based on a teaching methodology, derived from the Francophone strand of Didactics of Mathematics, known as Theory of Didactic Situations - TSD. Thus, the paper intends to extract some notions and essential aspects of the dialectical phases for teaching, with the scope of promoting a learning scenario capable of including and "seducing" noncompetitive students. To exemplify, the paper discusses two examples of Olympic Problems - OP -, originally inserted in a system of evaluation and "classification" of students with recognized abilities, but nevertheless, from the assumptions of TSD and the inclusion of technology, they are structured and described with the aim of encouraging the mobilization of differentiated and supportive reasoning in heuristics and strategies that, in general, remain restricted to the context of official preparation for Olympic mathematical competition.
\end{abstract}

Keywords: Olympic Didactic Situation. Mathematical Olympiads. Teaching. Technology.

RECEBIDO EM: 24/5/2018

ACEITO EM: 18/5/2020 
O contexto de desenvolvimento e da divulgação de uma cultura oriunda das Olimpíadas de Matemática envolve a disseminação de ideias matemáticas, de um estilo extremamente particular e pitoresco de sensibilização, sobretudo de jovens participantes interessados e, também, de muitos curiosos que, em maior ou em menor substância, carregam consigo um intrínseco envolvimento e uma percepção subjetiva de admiração, e da identificação da estética e da beleza, oriundas do saber matemático, nem sempre aflorado e/ou estimulado de forma adequada em outros contextos demasiadamente gerais.

Ademais, as raízes históricas, sociais e epistemológicas confirmam que o crescimento paulatino, progressivo e irrefreável do conhecimento científico matemático sucedeu, de modo indubitável, a partir do enfrentamento e da solução de vários problemas não triviais, por vezes de ordem prática e, por vezes, estritamente abstratos e complexos. Da mesma forma, registramos figuras emblemáticas no passado, como matemáticos ilustres envolvidos em intensas contendas e desafios de natureza pública que, de modo resumido, culminavam para o desafio intelectual e de superação, por intermédio da proposição de solução de problemas competitivos ou, até mesmo, saudáveis provocações entre pares.

De modo metafórico, muitos elementos que identificamos nos jogos olímpicos gregos podem ser observados, respeitando-se determinados aspectos intrínsecos e que muito se assemelham ao ambiente característico que ocorre no interior das Olimpíadas Brasileiras de Matemática. Posto que declaramos maior interesse pela Olimpíadas Brasileiras de Matemática da Escola Pública - Obmep -, podemos depreender e expectar algumas características semelhantes objetivadas nas Olimpíadas de Matemática, na medida em que envolve estimular a competição saudável entre vários jovens "prodígios", estudantes com talentos e habilidades matemáticas reconhecidamente acima da média e com rendimento intelectual distinguido, capaz de determinar as melhores colocações em certames nacionais e, porventura, em competições internacionais (CHAN, 2007).

Não obstante, nas seções subsequentes assinalaremos algumas preocupações com outros elementos que nem sempre se mostram visíveis ou proeminentes no processo e no contexto suprarrelatado. De fato, quando nos atemos ao papel dos professores de Matemática precisamos admitir que grande parte deles não participa diretamente da elaboração, da construção, da determinação/designação de questões e dos problemas que concorrem/determinam, intimamente, os respectivos níveis de apresentação, exigência e competição na Obmep. Por conseguinte, depreendemos que uma grande parcela ou grupo de profissionais que atua na simples execução e fiscalização da aplicação de provas ou, em casos extremos, de professores de Matemática, apresentam uma prática didática apartada e completamente distanciada do modelo e das nuances pitorescas da Matemática veiculada neste ambiente de inserção social.

Nossa segunda preocupação, e que constitui um dos argumentos que devem ser retomados mais adiante, diz respeito ao caráter "seletivo" e "classificador" da população de estudantes que participa de competições oficiais em Matemática. De modo inexorável, as três fases subsequentes da Obmep tendem a eliminar e desconsiderar uma grande quantidade de estudantes. Conjecturamos, então, a existência de uma quantidade ainda maior de estudantes não participantes das Olimpíadas, que perdem, de 
modo inquestionável, a oportunidade de ter um contato ímpar com toda uma cultura matemática que destoa de certas características, há tempos criticadas/reprovadas e que tendem, como costumamos registrar, a envidar o caráter reducionista/mecanicista e algorítmico-procedural.

Diante dos fatores anteriores, sublinhamos um último, vinculado ao elemento imprescindível de maior compreensão e entendimento do papel e da missão do professor de Matemática, concernente ao tipo das características e da natureza de um raciocínio matemático que, a partir da primazia das interações adequadas promovidas entre os estudantes - professor - conhecimento, deve culminar com uma duradoura e real incorporação e aquisição de novas formas de conhecimento ao patrimônio cognitivo dos sujeitos. Isso posto, demarcaremos nosso contexto de interesse em seguida.

\section{SOBRE OLIMPÍADAS INTERNACIONAIS E NACIONAIS, COMPETIÇÕES MATEMÁTICAS E A RESOLUÇÃO DE PROBLEMAS}

Decididamente, no âmbito da História da Matemática (ACZEL, 1996; DORRIE, 1965; KRANTZ, 2000; MOLCHANOV; TOLPYGO, 1969; STEWART, 2013; WEIL, 1991) observamos uma atividade geneticamente estruturadora e que contribui, de modo ímpar, para o crescimento irrefreável e ininterrupto da Matemática (WEIL, 1991). Com efeito, de modo contumaz, encontramos em vários livros de História da Matemática - $\mathrm{HM}-\mathrm{O}$ relato de diversos autores indicando a ocorrência de torneios e desafios envolvendo matemáticos que, a depender da natureza intrínseca e da tradição do problema envolvido, proporcionaram situações de tensão entre os competidores ou que, em outros casos, revelaram um intelecto privilegiado e repertório de habilidades matemáticas distinguidas.

Para exemplificar, Koshy (2014, p. 31) comenta que Pierre Fermat (1607-1665), em 1657, desafiou o matemático inglês John Wallis (1616-1703) e o Lord William V. Brouncker (1620-1648) a resolver a equação diofantina não linear indicada por $x^{2}-d y^{2}=1$, onde $d$ é um não quadrado e positivo. Koshy (2014, p. 31) acentua, entretanto, que os matemáticos indianos buscaram resolver tal equação em 800 e 650 anos depois de Cristo. O matemático indiano Brahmagupta escreveu que "uma pessoa que pode solucionar a equação $x^{2}-92 y^{2}=1$ em um ano é um matemático" (KOSHY, 2014, p. 31). Ainda em 1768, Joseph Louis Lagrange (1736-1813) apresentou um método para a resolução da equação anterior, empregando e adaptando as ideias de Leonhard Euler (17071783). A tradição matemática dos indianos revela-se nos dias atuais, por exemplo, no contexto das Olimpíadas Indianas de Matemática e nas Olimpíadas Internacionais de Matemática (OIM). Neste sentido, Prasad (2018) recorda o seguinte contexto histórico:

Olimpíada Internacional de Matemática (OIM) é um grande evento no cenário matemático mundial de hoje, apresentando quase 100 países diferentes, mas começou em uma quantidade muito pequena. A primeira OIM foi realizada em 1959, quando a Romênia convidou um pequeno número de países do que era então conhecido como Bloco Oriental para participar do evento. Os sete países seguintes participaram desta OIM: Romênia, Hungria, Tchecoslováquia, Bulgária, Polônia, União das Repúblicas Socialistas Soviéticas (URSS, mais conhecida 
como União Soviética; a União deixou de existir em 1991) e República Democrática Alemã (mais comumente conhecido como Alemanha Oriental; note que a Alemanha Ocidental e a Alemanha Oriental unidas em 1989) (p. 85).

Por sua vez, Losada et al. (2011) discutem as condições necessárias de acesso e inclusão, cuja natureza envolve desafios matemáticos, tomando como caso de estudo três países, a saber: Singapura, Holanda e Brasil. Registramos, ainda, que Protasov et al. (2011) apresentam vários exemplos de categorias de problemas matemáticos desafiadores, com interesse de sua ocorrência no interior e fora da sala de aula. Os autores pontuam que muitos desafios intelectuais, envolvendo a Matemática, se constituem uma extensão natural das atividades ordinárias que ocorrem em sala de aula.

Na pesquisa internacional de Kenderov et al. (2011), registramos os vários exemplos de ambientes pedagogicamente organizados e planejados, visando à proposição de projetos efetivos de investigação. Kenderov et al. (2011) comentam, por exemplo, que:

O estilo das Olimpíadas Internacionais de Matemática (OIM) está sujeito e restrito a determinadas regras formais, que regulam cada aspecto da competição: participação, seleção minuciosa de problemas, acesso ao conteúdo das soluções, distribuição de medalhas e muitos outros detalhes essenciais (p. 58)

Kenderov (2006, 2009) desenvolve um expediente de análise e discussão desde os movimentos cronológicos de origem, em 1885, na Hungria, e seu desenvolvimento como ação inicial que buscou beneficiar estudantes do ensino primário. Nesse sentido, Kenderov (2009, p. 14) recordou o papel pioneiro e de vanguarda das competições Eötvös na Hungria, quando observa algumas de suas raízes rudimentares perspectivadas, relatando que,

Contudo, a competição de Eötvös na Hungria, em 1894, como sendo creditado o precurso dos concursos contemporáneos de Matemática e Física para secundários da escola. Os concorrentes receberam quatro horas para resolver três problemas (sem interação com outros alunos ou professores foi permitido). Os problemas na competição Eötvös foram projetados para verificar a criatividade e o pensamento matemático, não apenas habilidades técnicas adquiridas a priori. Em particular, os alunos foram convidados a fornecer uma prova de uma declaração. O modelo da competição Eötvös agora está amplamente difundido e ainda domina uma grande parte do cenário da competição.

Kenderov (2009) descreve, essencialmente, um aspecto impulsionador e primordial vinculado ao estilo distinguido de competição e dos desafios e verdadeiros duelos intelectuais, quando comenta no seguinte trecho:

A concorrência é essencial e intrínseca à vida. Todos os dias, os seres vivos na natureza e assuntos econômicos na sociedade competem por recursos, por melhores condições de vida e para maior eficiência. $O$ desejo de competir na superação de um desafio é profundamente enraizada na natureza humana e tem sido empregada durante séculos para ajudar as pessoas a aguçar suas habilidades e melhorar seu desempenho em várias atividades (KENDEROV, 2009, p. 1.583). 
Apesar de que os limites do trabalho atual não nos permitem ampliar/extrapolar nossa discussão sobre outros eventos históricos atinentes aos fenômenos da Olimpíadas de Matemática, tomando como referência um cenário internacional, iremos extrair alguns ensinamentos básicos dos aspectos indicados há pouco por Koshy (2014 ) e restringir-nos-emos ao contexto e cenário educacional brasileiro.

De imediato, averiguamos a mobilização de curiosos e competidores em torno do desafio intelectual, de um tirocínio tácito e de uma contenda sagaz, provenientes da resolução de problemas matemáticos que, tendo em vista o importante papel adquirido e referendado por um conjunto de insignes intelectuais e expoentes da Matemática no passado, podem conferir ao solucionador um autêntico papel distinguido social, intelectual e cientificamente reconhecido entre seus pares.

Segundo, "bons problemas" matemáticos carregam consigo, de modo intrínseco, elementos de resistência (resiliência), de aparente invulnerabilidade e proporcionam entraves que podem concorrer por anos ou, mesmo, até séculos de tentativas frustradas. Terceiro, não há outra via ou caminho para que possamos compreender o crescimento irrefreável do conhecimento cumulativo, a não ser a partir de uma hegemônica cultura matemática ocidental cujas raízes gregas indicam, consubstanciam e conferem sua importância e distinção social.

Ora, os argumentos anteriores repetem-se, se perpetuam, se fortalecem e atuam na replicação de inúmeras práticas e procedimento adotados em competições oficiais em nosso país, sobretudo relativo ao contexto do nosso interesse de atenção maior, que se enquadra nas maratonas sistemáticas promovidas e que recebem a sigla da Obmep. De modo standard, aparecem a partir de uma edição razoavelmente moderna e atualizada, envolvendo a sistemática da exposição de jovens, relativamente a um sistema de proposição de testes crescentes de dificuldades e que culmina, de modo extremo, em premiações e no laureamento estrategicamente perseguido, com a correspondente distinção social e o merecido reconhecimento dos finalistas e a visibilidade de suas instituições de origem.

A ideologia oficial da competição aqui consiste em conceder as medalhas de ouro, prata e bronze aos respectivos estudantes competidores, com a indicação da região do país, seguindo-se, ainda, do nome do estabelecimento de ensino que suscitou e promoveu uma formação diferenciada e exitosa para os vencedores. Por outro lado, manifestamos profundas preocupações com um outro aspecto ou "face da moeda".

Com efeito, não podemos desconsiderar uma grande quantidade de estudantes que, a depender de uma autoavaliação subjetiva e de inseguranças adquiridas com a Matemática, se afastam do viés standard e da forma social peculiar de conhecimento deste saber, irremediavelmente amparado por problemas e situações intrigantes, além da exigência ininterrupta de heurísticas resolutivas imediatas. Dessa forma, propugnamos um expediente capaz de atrair, aproximar e "seduzir" esses estudantes (não competidores) relativamente ao conhecimento matemático, segundo sua forma ou viés de apresentação competitiva e pela proposição diferenciada de problemas abordados nas olimpíadas. 
Outros sujeitos não menos importantes no processo referem-se aos professores de Matemática que não atuam diretamente no sistema de avaliação em Olimpíadas. Em certos casos, ocorre, em grande quantidade de ocasiões, de o professor desenvolver sua transposição didática direta e exclusivamente extraída dos livros didáticos, em cumprimento indefectível dos conteúdos, segundo um cronograma institucionalmente definido. Em outra classe de professores de Matemática, registramos os profissionais que atuam com turmas "especiais", com "turmas olímpicas" e, com elas, precisam apresentar um viés de abordagem, de mediação diferenciada e adequada ao ávido estilo competitivo dos participantes (BADARÓ, 2015; CARVALHO, 2013; COCCO, 2013).

Ora, aqui registramos nossa primeira dicotomia, tendo em vista a necessidade sine qua non de proporcionar o alcance, por parte dos estudantes, de elementos característicos que mais se aproximam ou atualizam do modus operandi de construção da Matemática em nossa cultura ocidental. Enquanto isso, outros sujeitos são expostos ao modelo algoritmizado e são encarregados da tarefa da resolução de dezenas de exercícios repetitivos que ensejam a memorização, e que, consequentemente, constituem variáveis que devem fornecer, de modo standard, os indicadores preocupantes relativamente ao ensino e aprendizagem de Matemática em nosso pais (FEITOSA, 2015; SILVA, 2016).

Diante de um quadro merecedor de maior atenção, assinalamos ainda que, em várias ocasiões, o professor de Matemática desenvolve sua praxis desprovida de um fundamento teórico para sua transposição didática e a inexistência de uma metodologia de ensino sistemática, declarada e dedicada ao tipo de abordagem característica das Olimpíadas.

Isso posto, doravante indicamos alguns aspectos da Teoria das Situações Didáticas - TSD - que detêm o potencial de repercutir para uma perspectiva de aperfeiçoamento da ação, mediação e eficiência do professor no seu locus de atuação, visando a uma mediação pedagógica que não desconsidera alguns dos indícios e/ou elementos supramencionados.

\section{A TEORIA DAS SITUAÇÕES DIDÁTICAS (TSD): Situando a Noção de Raciocínio Matemático}

A partir de uma tradição balizada por 30 anos de investigação, desenvolvida no continente europeu, a vertente da Didática da Matemática - DM - proporcionou a adoção de pontos de vista diferenciados em torno dos fenômenos originados do binômio clássico ensino-aprendizagem. De modo destacado, ainda no âmbito da DM, distinguimos a Teoria das Situações Didáticas - TSD - que, de modo prosaico, busca constituir um campo epistêmico e teórico, consubstanciado nas interações do trinômio clássico estudante (de Matemática)-professor (de Matemática)-conhecimento matemático. Dessa forma, a TSD proporciona a modelização de situação de ensino por intermédio da simplificação e da conceptualização de modelos e de categorias explicativas, gestadas e originadas da esfera de práticas do professor de Matemática e dos estudantes. 
O aspecto sui generis é originado de um campo de pesquisa que adquiriu o reconhecimento e o respaldo em diversos países, como aparato teórico e conceitual capaz de desenvolver um expediente de análise técnica, compreensão, descrição e, sobretudo, de controle e predição de fenômenos oriundos das interações do trinômio supracitado.

A TSD introduz um estatuto de discussão de teorias matemáticas, tomando como referências fundamentais as intenções de dois sujeitos importantes, a saber: o matemático profissional e o professor de Matemática. O profundo entendimento das semelhanças e diferenças, correspondentemente a cada sujeito epistêmico envolvido, permitirá extrair profícuas implicações que se endereçam aos fenômenos envolvendo o ensino de Matemática. Por exemplo, no excerto a seguir Brousseau (1986) distingue e pontua os diferentes estatutos e usos de noções matemáticas e de noções paramatemáticas, quando explica:

Mas, podemos dizer também, em se considerando o ponto de vista formal, mais sistêmico, que na ausência de um estatuto matemático, os termos utilizados são instrumentos, que respondem às necessidades de identificação, formulação e comunicação, e que seu uso (sua utilização) repousa sobre um controle semântico. Os matemáticos os empregam com eficiência, não apenas porque os mesmos possuem uma definição, que concede sobre o mesmo um controle sintático, mas, que eles conhecem bem e qualquer contradição que obrigue uma matematização a mais, e que possa surgir sobre o mesmo. Tal uso paramatemático corresponde a uma certa economia de organização teórica, portanto, economia de comunicação, ensino e a resolução de problemas (p. 343).

Resumidamente, parafraseando o pensamento de Douady (1995), os "conceitos paramatemáticos" funcionam precipuamente como instrumentos, enquanto os "conceitos matemáticos" desempenham o papel de objetos teóricos e conceituais. Ademais, oriundo ainda da cultura francesa, não podemos desconsiderar sua forte distinção entre a noção de saber (savoir) e de conhecimento (connaissance). A distinção e significação de origem francófona pode agregar um efeito positivo ao entendimento e uma percepção cuidadosa do professor de Matemática, concernentemente à sua própria mediação em sala de aula. Registramos algumas considerações e suas distinções logo em seguida.

A distinção entre um saber (savoir) e um conhecimento (connaisance) se deve, preliminarmente, ao seu estatuto cultural; um saber matemático (savoir) é um conhecimento institucionalizado. A passagem de um estatuto para outro implica, todavia, as transformações que o diferenciam e que lhe explica, a partir de relações didáticas, que se constroem com tal propósito. Mas admitiremos, em um primeiro momento, que os conhecimentos explicitáveis e os saberes (savoirs) intervêm de modo comparável ao controle dos julgamentos dos estudantes. Eles formam uma espécie de "código" e, com auxílio do mesmo, se constrói, se justifica, se verifica e demonstra as relações de validez (BROUSSEAU, 1986, p. 343).

Um exemplo importante de modelização ou simplificação do jogo dialético anterior encontra-se resumido por Douady (1984). De fato, este autor comentou e discutiu uma trajetória ou percurso capaz de organizar e discriminar as mudanças provocadas pelos estudantes, por meio e a partir da ação professor, de um modo produtivo, quando 
descreveu três formas dialéticas (situações) diferentes de manifestação ou tipologias distintas para o estatuto do conhecimento, tomando como referência a ação do professor, a saber:

Situação de ação: $O$ aluno é confrontado com uma situação que produz um problema. Na busca pela solução, ele produz ações que podem levar à criação de um conhecimento na ação. Ele pode, mais ou menos, explicitar ou validar suas ações, todavia, a situação não exige.

Situação de formulação: As condições diferentes possibilitam uma mudança de informações e a criação de uma linguagem para assegurar a mudança. Na situação de formulação, o estudante poderá justificar suas proposições, mas, a situação não exige.

Situação de validação: As mudanças não concernem somente mais simplesmente com as informações, mas, as declarações. É necessário provar o que foi afirmado, por intermédio da ação. É o objetivo de uma situação de validação.

Antes de indicar a última fase dialética que perspectivamos, cabem algumas considerações recentes de Margolinas e Drijvers (2015), quando explicam um importante movimento de transformação sofrido pelo conhecimento matemático.

Durante a construção social da Matemática, o conhecimento é formulado, formalizado e escrito. A utilidade inicial que foi o significado de uma situação específica se generaliza e se torna menos explícito ou mesmo escondido, um conhecimento matemático se torna um tipo de conhecimento formal. Este processo de institucionalização não pode ser evitado; e o mesmo servirá para fortalecer e simplificar o conhecimento matemático original, que é um aspecto da transposição didática (CHEVALLARD, 1985). O processo que conecta conhecimento em situação (connaissance) e o conhecimento institucional (savoir), trabalham em ambas as direções ( $\mathrm{p}$. 899).

Dessa forma, a partir das explicações de um movimento ou conjunto de transformações finais que devem incidir sobre o conhecimento matemático, teremos, finalmente, a situação ou fase dialética de institucionalização, que é assim caracterizada:

É uma situação em que se desvenda a passagem de um conhecimento e seu papel de resolução para a ação, de formulação e de prova, para um novo papel, como de referências para realizações futuras, pessoais e coletivas. [...] A institucionalização comporta, portanto, uma mudança de convenção entre os atores, um conhecimento (justificado ou não) de sua validade e da utilidade de um conhecimento e modificação de um conhecimento (BROUSSEAU, 2010, p. 11).

Os momentos ou fases dialéticas anteriores, derivadas da tese de Brousseau (1986), preservam grande fecundidade para o ensino e a atuação do expert. Reconhecemos, todavia, como algumas repercussões da pesquisa pioneira de Brousseau (1986, 1997, 2010, 2011), determinados elementos e preocupações discutidas com maior precisão, ocorreram somente décadas depois da publicação de sua tese de Doutorado.

De fato, Brousseau e Gibel $(2005$, p. 6) observam que em uma situação didática "o professor age para obter sinais de que seus alunos estão conscientes do que ele queria ensinar. Esses sinais devem ser evidentes nas produções infantis. O professor consegue perceber o que ele quer ensinar apenas interpretando as formas e condições dessas 
produções". Aqui, surge um componente imprescindível atinente ao papel do professor, a saber: um entendimento sobre as funções, manifestação e as características de um raciocínio matemático revelado nas produções dos estudantes.

Brousseau e Gibel (2005, p. 17) modelizaram, então, a noção de raciocínio matemático. Para tanto, explicam um raciocínio de natureza inferencial, como uma relação $R$ entre os elementos de um conjunto $A$ e um conjunto $B$, de sorte que: (i) $A$ denota uma condição ou fato observado, que pode ser contingente sob determinadas circunstâncias particulares; (ii) B é consequência, uma decisão ou fato predicativo; (iii) R é uma relação, regra, ou geralmente algo considerado como conhecido e relativamente aceito. A relação $\mathrm{R}$ conduz uma ação registrada e circunstanciada. Simplificadamente assumiremos a notação $A \mapsto B$ para designar uma forma de raciocínio inferencial.

Gibel e Brousseau (2005, p. 18) explicam que "a função de um raciocínio varia de acordo com o tipo de situação que levamos em consideração, como no caso em que temos uma situação de ação, formulação, validação e institucionalização". Um elemento que apontamos e que envolve um caráter de não trivialidade diz respeito, de modo preciso, ao caráter de sua correspondente variação da natureza, da função, das características do raciocínio a ser mobilizado ao decurso de uma situação de ensino, amparada pela TSD (ação, formulação, validação e institucionalização).

De modo esquemático, na Tabela a seguir trazemos algumas características do raciocínio intuitivo (ALVES, 2012) e do raciocínio lógico, extraídas também da descrição de Brousseau e Gibel (2005), e que requerem atenção adequada por parte do professor.

Tabela 1 - Descrição das tipologias de raciocínio mobilizados em cada fase da TDS

\begin{tabular}{|c|c|c|}
\hline Fases da TSD & Raciocínio lógico & Raciocínio intuitivo \\
\hline $\begin{array}{l}\text { Situação de } \\
\text { ação }\end{array}$ & $\begin{array}{l}\text { Não priorizado ou distinguido, tendo em } \\
\text { vista o estímulo na formação e mobiliza- } \\
\text { ção da maior quantidade de representa- } \\
\text { ções possíveis envolvidas no problema. } \\
\text { Não presente, de modo prioritário. } \\
\end{array}$ & $\begin{array}{l}\text { Mobilizado com origem na visualiza- } \\
\text { ção e a percepção tácita de proprie- } \\
\text { dades de natureza numérica, nature- } \\
\text { za algébrica e natureza geométrica. } \\
\text { Não inferencial. }\end{array}$ \\
\hline $\begin{array}{l}\text { Situação de } \\
\text { formulação }\end{array}$ & $\begin{array}{l}\text { Forma inferencial } A \stackrel{R}{\longmapsto} B \text { registrada } \\
\text { nas primeiras estratégias formuladas } \\
\text { e executadas, todavia não justificadas } \\
\text { completamente pelos estudantes. Sis- } \\
\text { tema notacional correlato definido e } \\
\text { mobilizado, função de instrumento. }\end{array}$ & $\begin{array}{l}\text { Significados e sentido das ações e es- } \\
\text { colhas dos estudantes não possuem } \\
\text { uma justificativa lógica, tácita e ime- } \\
\text { diata, de modo a concorrer para um } \\
\text { viés conscientemente explicado pelo } \\
\text { estudante. }\end{array}$ \\
\hline $\begin{array}{c}\text { Situação de } \\
\text { validação }\end{array}$ & $\begin{array}{l}\text { Forma inferencial de pensamento } \\
\qquad \stackrel{R}{\mapsto} B \text { parcial ou totalmente justifica- } \\
\text { da, razões de ordem lógico-matemática } \\
\text { que confirmam ou rejeitam determina- } \\
\text { do argumento. }\end{array}$ & $\begin{array}{l}\text { Seu papel mostra-se reduzido, mas } \\
\text { não completamente eliminado do } \\
\text { processo de resolução de problemas. } \\
\text { Significados e sentido das ações em } \\
\text { torno de objetos teóricos e conceitu- } \\
\text { ais da Matemática. }\end{array}$ \\
\hline
\end{tabular}




\begin{tabular}{|c|c|c|}
\hline $\begin{array}{l}\text { Situação de } \\
\text { institucionali- } \\
\text { zação }\end{array}$ & 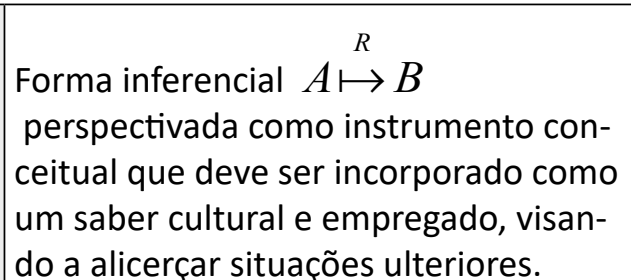 & $\begin{array}{l}\text { Formas refinadas de pensamento } \\
\text { idiossincrásico, de significados e sen- } \\
\text { tidos que deverão apoiar um novo } \\
\text { aprendizado circunstancial e particu- } \\
\text { lar que deriva a uma aprendizagem } \\
\text { futura. }\end{array}$ \\
\hline
\end{tabular}

Fonte: Elaboração do autor.

Inequivocamente, os elementos suprarresumidos e balizados pelas fases de ação formulação, validação e de institucionalização não ensejam provocar um processo simplificacionista do momento de ensino, mas, no entanto, podem referendar a mediação do professor para o desenvolvimento de uma Situação Didática Olímpica - SDO -, objetivando o contexto de ensino de Problemas Olímpicos.

\section{A NOÇÃO DE SITUAÇÃO DIDÁTICA OLÍMPICAS (SDO) E A ATUAÇÃO DO PROFESSOR}

Na seção anterior identificamos alguns elementos oriundos da TSD. Ademais, para efeito de uma maior sistemática de emprego das fases de ação, formulação, validação e institucionalização, algumas características essenciais dos tipos de raciocínios devem ser mobilizadas pelo expert, que se vinculam, de modo inexorável, ao expediente de avaliação do professor de Matemática no decurso de uma transposição didática.

Nas seções pregressas pontuamos, de modo en passant, alguns elementos do contexto das Olimpíadas de Matemática das escolas públicas no contexto internacional. Ademais, assinalamos alguns problemas que se originam de um processo natural de exclusão de estudantes que não participam direta e oficialmente de competições, mas que necessitam preservar um contato maior com a Matemática veiculada, segundo um viés particular de competição e superação visionada de obstáculos. Desse modo, a fim de demarcar alguns componentes imprescindíveis em nossa discussão, apresentamos as seguintes definições teóricas que constituem aplicações da TSD e encontram, ainda, um respaldo ou terreno de vacuidade na literatura (ALVES, 2020).

Problema Olímpico (PO): um conjunto de situações problemas de Matemática, abordado em um contexto competitivo ou de maratonas, com a participação apenas (e de modo restritivo) dos estudantes competidores, cuja abordagem e características de ação individual e solitária destes envolve apenas objetivo/escopo de se atingir as metas (medalhas e certificados) definidas a priori em cada competição por intermédio do emprego de estratégias especializadas, raciocínios e argumentos matemáticos eficientes, instrumentalizados previamente por professores de Matemática.

Situação Didática Olímpica (SDO): um conjunto de relações estabelecidas implícita ou explicitamente, balizado por uma metodologia de ensino (TSD) entre um aluno ou grupo(s) de alunos, um certo meio (compreendo, ainda, o conhecimento matemático abordado por intermédio de problemas de competição e de olimpíadas) e um sistema educativo, com o objetivo de permitir a apropriação, por parte destes alunos, a um co- 
nhecimento constituído ou em vias de constituição, oriundo de um ambiente de competição coletiva e debate científico do grupo, a competição solidária e problemas ou conjunto de problemas característicos e abordados nas olimpíadas de Matemática.

De modo prosaico, a noção de SDO que concebemos, apresentamos e definimos anteriormente, é acrescida e fundamentada a partir da noção de situação didática (BROUSSEAU, 1986, 2010), derivada da TSD, que é endereçada, de uma maneira geral, para os fenômenos de ensino e a aprendizagem em Matemática. Caracterizaremos, de um ponto de vista notacional ou equação mnemônica, uma Situação Didática Olímpica - SDO pela seguinte equação característica $S D O=\left(T S D_{\text {metodologia }}+P O_{\text {problema olimpico }}\right)$.

Cabe observar, todavia, um extenso repertório ou nomenclaturas e "etiquetas" cunhadas e produzidas a partir de uma tradição da pesquisa em torno do ensino e da aprendizagem, cujo legado da cultura francófona remonta ao final dos anos 70 e início dos 80 do século 20. Por tal via, Chevallard $(1982$, p. 7) explica que "a questão crucial do nominalismo em uma atividade é o peso que exerce a etiqueta sobre o que a mesma designa. A coisa deve possuir mérito para o nome que atribuímos. O nome, por sua vez, comunica certos entraves concernentes ao seu referente".

Assim, poderemos compreender a produção de um conjunto representativo de definições ou "etiquetas" na fundamentação proposta por Brousseau (1986), com o escopo precípuo de modelizar e, assim, observar/analisar, simplificadamente, relações educacionais particulares que, de modo natural, se evidenciam extremamente complexas.

Na Tabela 2 apresentamos algumas relações características oriundas da nossa definição de Situação Didática Olímpica - SDO. Tais características devem funcionar no sentido de modelizar e promover situações de ensino de Matemática envolvendo a exploração de POs em sala de aula, com o arrimo da tecnologia.

Tabela 2 - Descrição e distinção entre as noções de PO e SDO, amparo na TSD

\begin{tabular}{|c|l|l|}
\hline Características & \multicolumn{1}{|c|}{ Problema Olímpico (PO) } & \multicolumn{1}{c|}{ Situação Didática Olímpica (SDO) } \\
\hline $\begin{array}{c}\text { Dos problemas } \\
\text { envolvidos }\end{array}$ & $\begin{array}{l}\text { Problemas de competições, } \\
\text { elaborados e estruturados de } \\
\text { forma serial, tendo em vista } \\
\text { a aplicação dos três níveis } \\
\text { hierárquicos previstos pela } \\
\text { Obmep em competições. }\end{array}$ & $\begin{array}{l}\text { Problemas de competições readaptados, } \\
\text { reetruturados, modificados e } \\
\text { circunstanciados, tendo em vista um } \\
\text { grupo ou grupos de alunos particulares, } \\
\text { com o amparo da TSD. }\end{array}$ \\
\hline $\begin{array}{c}\text { Dos } \\
\text { competidores }\end{array}$ & $\begin{array}{l}\text { Ação individual de participação } \\
\text { nas etapas das Obmep, visando } \\
\text { à obtenção de colocações } \\
\text { distinguidas no certame. }\end{array}$ & $\begin{array}{l}\text { Ação e trabalho em equipe, visando } \\
\text { investigação científica e à evolução } \\
\text { coletiva do conhecimento do grupo. }\end{array}$ \\
\hline Do professor & $\begin{array}{l}\text { Não presente. Equipes de de } \\
\text { profissionais especialistas na na } \\
\text { confecção/produção de questões } \\
\text { visando à seleção (identificação) } \\
\text { de prodígios e medalhistas. }\end{array}$ & $\begin{array}{l}\text { Promotor da situação de ação, situação } \\
\text { de formulação, situação de validação e } \\
\text { a institucionalização do conhecimento } \\
\text { matemático para o grupo ou grupos de } \\
\text { competidores em sua própria sala de } \\
\text { aula. }\end{array}$ \\
\hline $\begin{array}{c}\text { Uso e emprego } \\
\text { da tecnologia }\end{array}$ & $\begin{array}{l}\text { Ausente e não prevista sua } \\
\text { exploração em certames oficiais } \\
\text { ou competições nacionais. }\end{array}$ & $\begin{array}{l}\text { Empregada para resultar nas alterações, } \\
\text { modificações necessárias e adaptação } \\
\text { para o grupo ou grupos de estudantes. }\end{array}$ \\
\hline
\end{tabular}




\begin{tabular}{|c|c|c|}
\hline Dos objetivos & $\begin{array}{l}\text { Seleção, classificação. Distinção } \\
\text { social para os alunos mais } \\
\text { eficientes e notáveis no certame, } \\
\text { objetivando a certificação e o } \\
\text { laureamento. }\end{array}$ & $\begin{array}{l}\text { Promoção do grupo ou grupos de } \\
\text { estudantes com habilidades acima } \\
\text { da média, bem como estudantes } \\
\text { com poucas chances de maior êxito } \\
\text { individual. }\end{array}$ \\
\hline
\end{tabular}

Fonte: Elaboração do autor.

Na seção seguinte, a partir da eleição de dois POs, estruturamos um percurso de abordagem metodológica tomando como referência as fases previstas pela TSD.

\section{DOIS EXEMPLOS DE SDO}

Nesta seção, com o balizamento de vários elementos oriundos das seções predecessoras, discutiremos dois POs na medida em que fazemos aderir à nova noção de SDO. Assinalamos, mais uma vez, que, a partir dos enunciados dos problemas presentes no instrumento oficial aplicado ao decurso das fases das Olimpíadas Brasileiras de Matemática, indicaremos e descreveremos formas diferenciadas de exploração e modificação deste conteúdo e, assim, vislumbramos a mediação prevista e incorporada à noção de SDO como um viés de metodologia para o ensino que possa incluir, considerar e sensibilizar uma quantidade maior de estudantes, como temos enfatizado aqui, não competidores. Mostraremos que a tecnologia desempenhará um papel imprescindível na alteração da transposição do professor (ARTIGUE, 2013). Na Figura 1 vemos o enunciado.

Figura 1 - Exemplo de um Problema Olímpico - PO - presente na

Olimpíadas de Matemática 2016, na 1a fase e nível um

18. Na figura, as medidas são dadas em centímetros. Qual é a área da região cinzenta no interior do quadrado em centimetros quadrados?
a) $\frac{56}{5}$
b) $\frac{44}{3}$
c) 22
d) $\frac{68}{3}$
e) 24

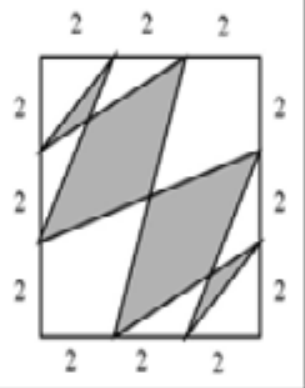

Fonte: Obmep, 2016.

Assim, o enunciado do nosso primeiro exemplo pode ser observado na Figura 1. Depreendemos, facilmente, que a área estática ou região de visualização (na cor cinza) constitui um dos objetivos principais requeridos na tarefa. Por outro lado, na Figura 2 definimos o seletor móvel "a" com a variação $0 \leq a \leq 6$.

De imediato, a ação de transformação/modificação e transposição didática do professor será um fator diferencial, na medida em que alguns elementos explícitos e, sobretudo, outros elementos implícitos no enunciado anterior, nomeadamente algumas propriedades numéricas e de invariância métrica, podem ser registradas, manipuladas e conjecturadas pelos grupos participantes, com origem na interação imediata com o software e o debate científico (ROGALSKI, 1990) deflagrado em sala de aula. 
Figura 2 - A visualização promovida pelo software possui papel e função fundamental no estabelecimento do debate e a troca de informações primárias com o grupo ao decurso de uma SDO

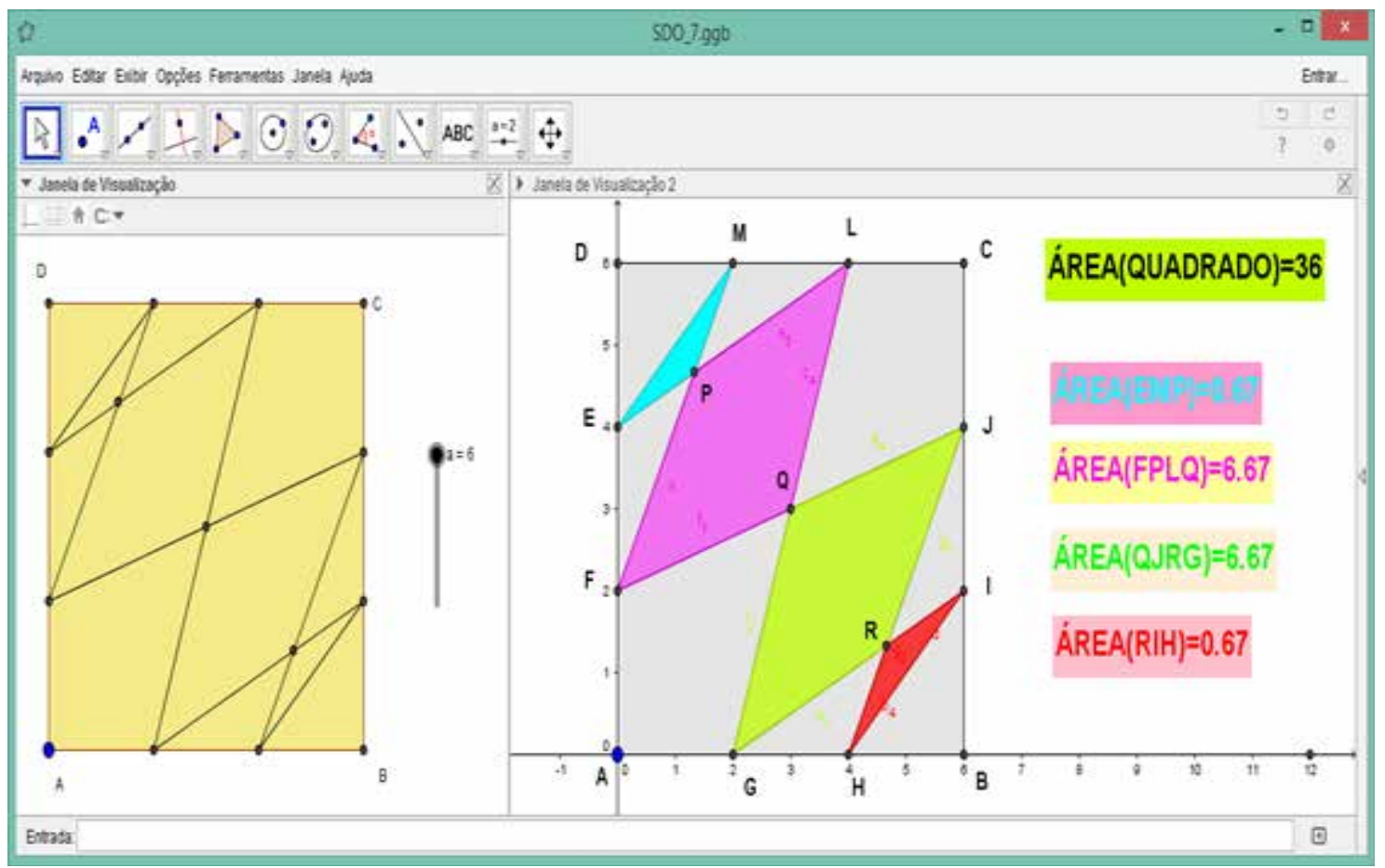

Fonte: Elaboração do autor.

Situação de ação: segundo os pressupostos que assumimos, a exploração visual da construção exibida na Figura 2 deverá estimular o entendimento de propriedades essenciais. Os estudantes podem observar, ao lado direito, o valor numérico das áreas dos polígonos indicados nas cores azul claro, rosa, verde e vermelho.

No momento preliminar, a atividade de visualização e da produção de conjecturas acerca da referida construção dinâmica apresentada é importante. Assim, os pontos indicados (ao lado direito da Figura 2) por A, B, C, D, E, F, G, H, I, J devem determinar segmentos que podem ser identificados pela propriedade elementar indicada por $2=\overline{D M}=\overline{M L}=\overline{L C}=\overline{J I}=\overline{C J}=\overline{I B}=\overline{B H}=\overline{H G}=\overline{G A}=\overline{A F}=\overline{F E}=\overline{D E}=2$.

Preliminarmente, a construção do software poderá ser explorada pelo grupo e, a despeito das alterações dinâmicas do seletor móvel, devem compreender a seguinte invariância de áreas Area $(\triangle E M P)=\operatorname{Area}(\triangle R I H)$ e Área $(\triangle F P L Q)=\operatorname{Á} r e a(\triangle Q J R G)$. A simetria da Figura deverá ensejar e proporcionará o registro de várias propriedades. Preliminarmente, os estudantes podem constatar que o triângulo $\triangle A E B$ é isósceles, cuja área é dada por $\frac{2 \cdot 2}{2}=2=\triangle A E B$. Por outro lado, podem observar que $\triangle O G H=\frac{\overline{G F} \cdot \overline{O F}}{2}=\frac{2 \cdot 3}{2}=3$ pois $\mathrm{F}$ é o ponto médio do lado (Figura 2, ao lado esquerdo).

Ademais, sendo o ponto " $\mathrm{O}$ " o centro do quadrado indicado na Figura, a área do triângulo é ${ }_{\triangle A G C}=\frac{\overline{A G} \cdot \overline{A C}}{2}=\frac{4 \cdot 4}{2}=8$.

Do mesmo modo, outro triângulo isósceles, cuja área pode ser avaliada de imediato, é no caso do triângulo $\triangle D A H=\frac{\overline{A H} \cdot \overline{A D}}{2}=\frac{6 \cdot 6}{2}=18$. Com esses dados numéricos preliminares, cuja determinação envolve a visualização das Figuras 2 e 3, a situação de em- 
prego de uma estratégia instala-se na fase dialética subsequente e que deve ser guiada pela construção subsequente que apresentamos na Figura 3. Reparemos, na Figura, os valores numéricos exibidos e iguais que correspondem, respectivamente, às áreas indicadas: $A R E A(\triangle E B I)=A R E A(\triangle I P Q)=A R E A(\triangle P Q R)=0.46$.

Situação de formulação: Almouloud (2007, p. 38) esclarece que, neste momento, a troca de informações e mensagens entre os estudantes é imprescindível. Ademais, o resultado do debate e da dialética "permite criar um modelo explícito que pode ser formulado com sinais e regras comuns". Como explicamos na fase dialética anterior, os estudantes precisam se apropriar de um sistema notacional.

Ademais, como acentua Artigue (1984, p. 7), prevemos que "o estudante poderá justificar suas escolhas, todavia, a situação não exige". Agora, ao lado esquerdo, poderemos determinar a área da região indicada pela relação Quadrilátero $(\mathrm{CGHD})=\triangle D A H-\triangle A G C=18-8=10$ (ver Figura 3, ao lado esquerdo). Então, os estudantes podem determinar a área do triângulo $\triangle C G O$ (ver Figura 3, ao lado direito).

De fato, a área do triângulo $\triangle C G O$ (ver Figura 3) pode ser avaliada segundo a decomposição. Ademais, as áreas dos triângulos semelhantes são $\triangle B E I \cong \triangle I G C$ (opostos pelo vértice). Com efeito, a estratégia será dividir (decompor) o triângulo $\triangle I G C$ em, exatamente, quatro triângulos (ver Figura 3, ao lado direito) e, além disso, de mesma área.

A propriedade importante, que deve ser estimulada ao decurso da investigação do grupo, diz respeito ao fato de que na decomposição ocorre quatro triângulos exatamente de mesma área.

Desse modo, podem tomar como " $\mathrm{x}$ " o valor da área do triângulo $\triangle B E I \mathrm{e}$, por conseguinte, decorre que a área é $A R E A(\triangle I G C)=4 x$. Facilmente podemos determinar a área do triângulo retângulo $\triangle A B G$ que indicamos por $A R E A(\triangle A B G)=\frac{2 \cdot(2+2)}{2}=4 \mathrm{e}$, analogamente, determinamos $A R E A(\triangle A E B)=\frac{2 \cdot 2}{2}=2$. Assim, poderemos determinar a área do triângulo $\triangle E I G$ da forma $A R E A(\triangle E I G)=A R E A(\triangle E I G)-A^{\prime} R E A(\triangle A E B)-A^{\prime} R E A(\triangle E I B)$ e, fazendo as contas: $A R E A(\triangle E I G)=4-2-x=(2-x)$ (ver Figuras 3 e 4). 


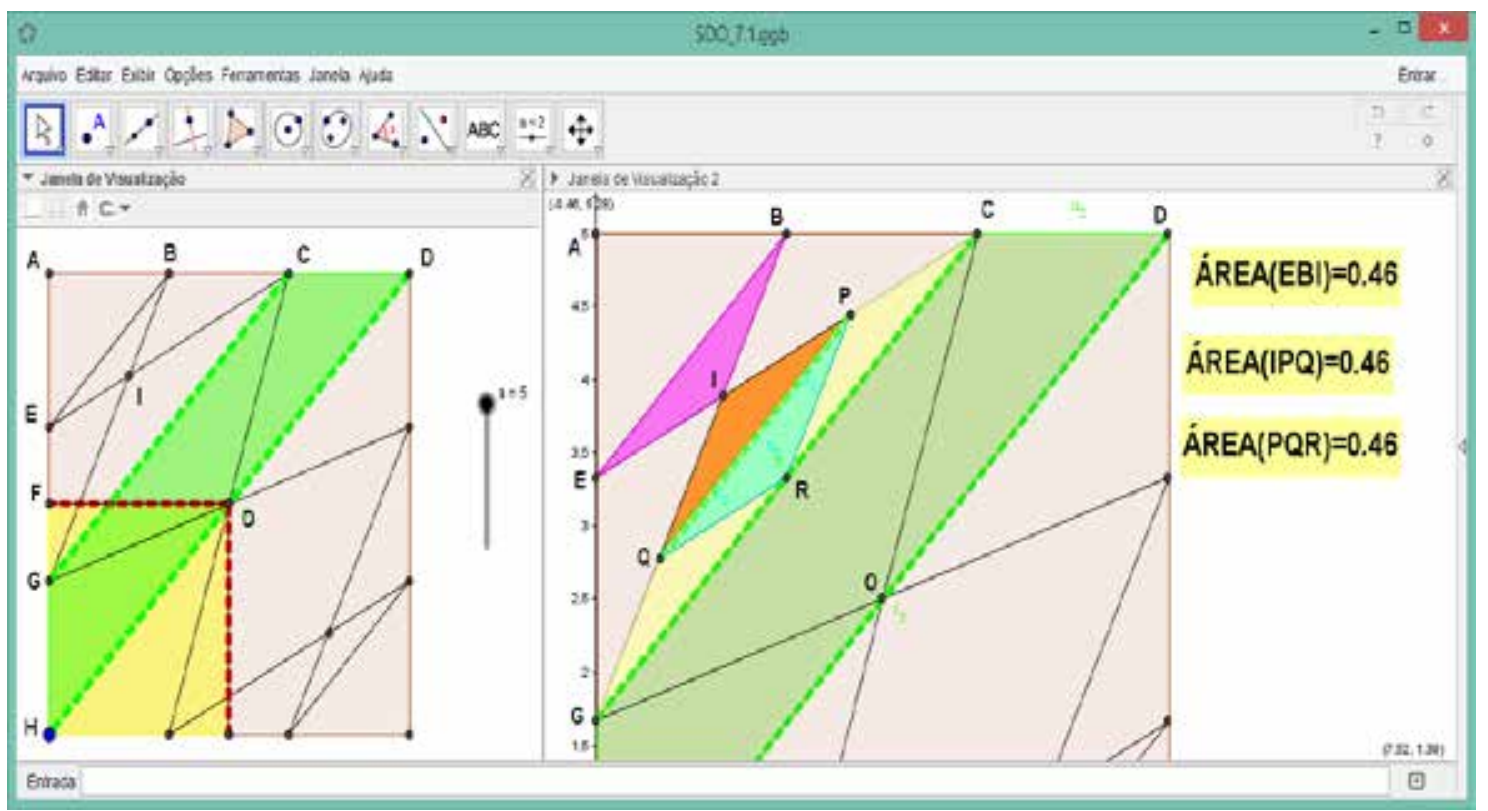

Fonte: Elaboração do autor.

Logo, em seguida, devem considerar o triângulo isósceles $A R E A(\triangle A G C)=\frac{4 \cdot 4}{2}=8$ e, dessa forma, podem determinar a área de um outro quadrilátero, e devem indicar $A R E A(\triangle B E G C)=A R E A(\triangle A G C)-A R E A(\triangle A E B)=8-2=6$. Finalmente, devem encontrar a seguinte relação: $x+4 x+2(2-x)=6 \leftrightarrow 3 x=2 \leftrightarrow x=\frac{2}{3}$. Por último, a área da região cinza, contida no triângulo $\triangle A H D$, deve valer a soma: $(5 x+4)=5 \cdot \frac{2}{3}+4=\frac{22}{3}$ e, tendo em vista a simetria identificada e/ou visualizada da Figura 4, devem determinar o seguinte valor $2 \cdot \frac{22}{3}=\frac{44}{3}=14.66$ e que, quando comparam e relacionam com os valores numéricos (que exibimos na Figura 2), podem notar e confrontar que vale a seguinte relação numérica que indicamos $2 \cdot \frac{22}{3}=\frac{44}{3}=14.666667=2 \cdot(6,67)+2 \cdot(0,67)$ (ver Figura 2). 
Figura 4 - Com o software GeoGebra o professor institui as alterações necessárias visando a adaptar a SDO ao seu público particular de estudantes

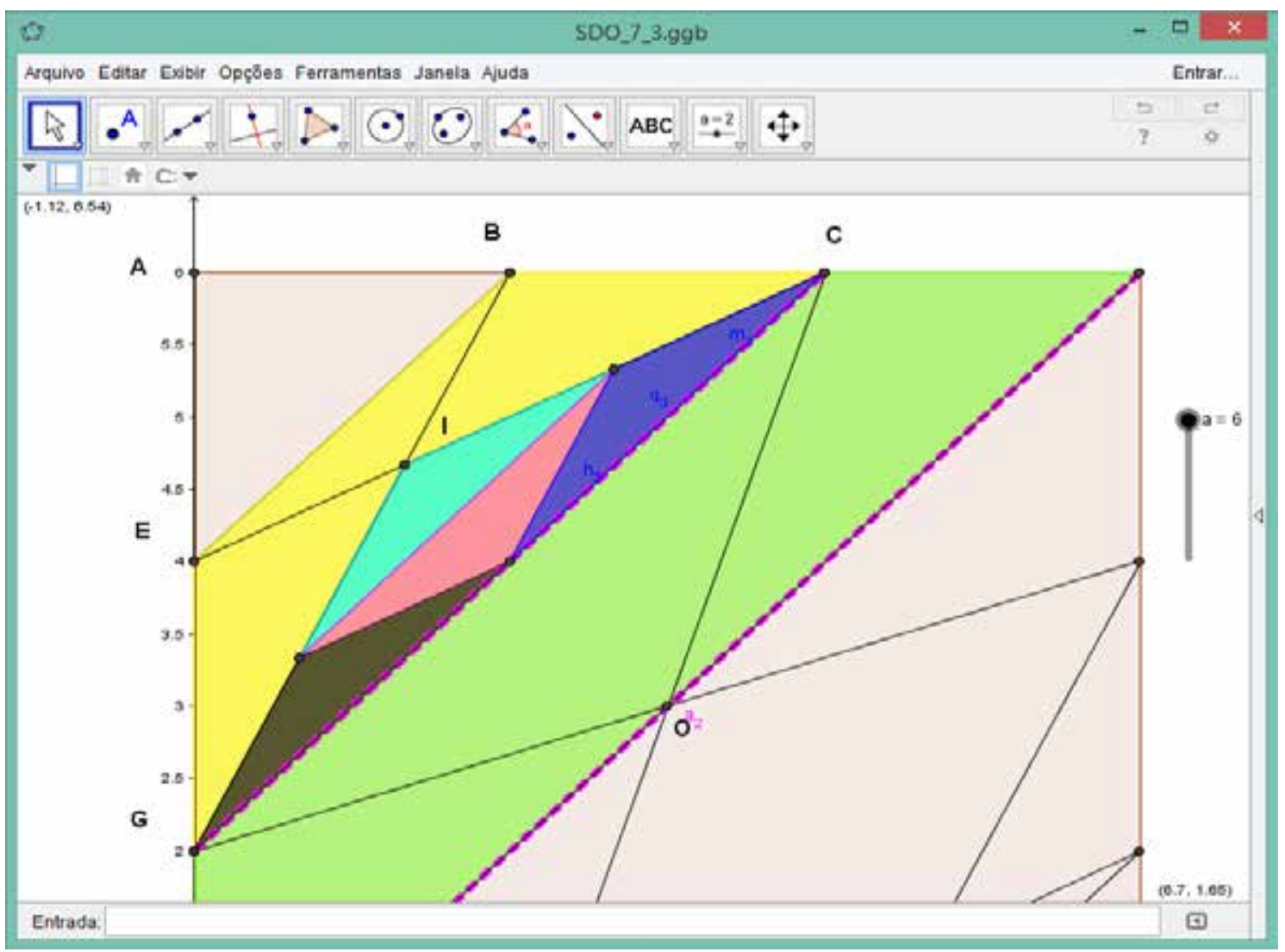

Fonte: Elaboração do autor.

Situação de validação: nessa fase, num contexto do "debate da certeza das asserções" (ALMOULOUD, 2007, p. 40), os dados são produzidos com origem nas interações dialéticas dos estudantes da fase anterior, com as informações e inferências empregadas a fim de obter a certeza das relações estabelecidas.

A mediação do professor será determinante no sentido de não permitir que os dados e conjecturas produzidas a partir da exploração do software, nas fases anteriores, não sejam desperdiçadas e, na fase final, possam concorrer para a avaliação final da evolução do grupo. Neste momento, o professor de Matemática deve estimular a identificação de todos os teoremas formais e definições matemáticas formais que referendam as escolhas anteriores.

Registramos na presente fase dialética de mediação prevista pela TSD, o predomínio de um raciocínio eminentemente inferencial do tipo caracterizado por $A \mapsto B$ e que não possuía a mesma proeminência ou importância das fases anteriores (ver Tabela 1).

Nesse caso, a visualização e percepção dinâmica de propriedades geométricas, algébricas e propriedades invariantes numéricas, assumiram um papel imprescindível, concorrendo para o entendimento progressivo a respeito da decomposição das figuras planas e suas relações de semelhança, originalmente estáticas. Agora, poderá comparar/confrontar os dados produzidos a partir da interação com software GeoGebra, visando à investigação resolutiva, com as estratégias oficiais previstas no espelho de resolução proposta no gabarito oficial da Obmep (ver Figura 5). 
Figura 5 - Exemplo das estratégias previstas na resolução do PO no contexto competitivo

Podemos dividir o triângulo IGC em quatro triângulos "iguais" ao triângulo BEI, conforme figura ao lado. Logo, se $x$ é a área do triângulo BEI então $4 x$ é a área do triângulo IGC. O triângulo $\mathrm{ABG}$ tem área $\frac{2 \times 4}{2}=4 \log$ a área do triângulo EIG é igual a $4-(2+x)=2-x$. Como a área do quadrilátero BEGC é $8-2=6$, temos $x+4 x+2(2-x)=6 \Leftrightarrow 3 x=2 \Leftrightarrow x=\frac{2}{3}$. Portanto, a área da

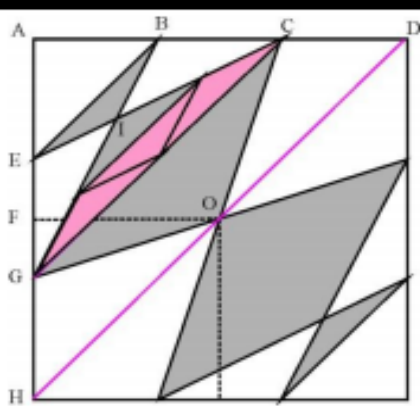
região cinzenta contida no triângulo AHD é igual a $5 x+4=5 \cdot \frac{2}{3}+4=\frac{22}{3}$. Logo, a área da região cinzenta, pela simetria da figura, é igual a $2 \times \frac{22}{3}=\frac{44}{3}$.

Fonte: Gabarito e resolução indicado no banco de provas da Obmep (2016).

Mais uma vez assinalamos que as inferências predominantemente simplificadas e indicadas no gabarito escondem ou encobrem muitas informações e várias possibilidades de conhecimentos mobilizados, de natureza tácita, intuitiva e, não necessariamente, se enquadram nas características de um raciocínio lógico-dedutivo (ALVES, 2012) (Tabela 2). Aqui, a mediação do professor será determinante, no sentido de detalhar/ pormenorizar outros caminhos/roteiros e alternativas de resolução indicados nas Figuras 5 e 6.

Figura 6 - Exemplo das estratégias previstas na prova das Olimpíadas e que são o objeto de uma transposição didática objetivando a natureza de uma SDO

18. (B) $\mathrm{Temos} \mathrm{AB}=\mathrm{BC}=\mathrm{CD}=\mathrm{AE}=\mathrm{EG}=\mathrm{GH}=2$.

A área do triângulo AEB é igual $\mathrm{a} \frac{2 \times 2}{2}=2$. A área do triângulo $\mathrm{OGH}$ é $\frac{2 \times 3}{2}=3$, pois $\mathrm{OF}=3$, pois $\mathrm{F}$ é o ponto médio do lado $\mathrm{AH}$ e $\mathrm{O}$ é o centro do quadrado. A área do triângulo $\mathrm{AGC}$ é $\frac{4 \times 4}{2}=8 \mathrm{e}$ a área do triângulo $\mathrm{DAH}$ é $\frac{6 \times 6}{2}=18, \log 0$ a área do quadrilátero CGHD é $18-8=10 \mathrm{e}$,

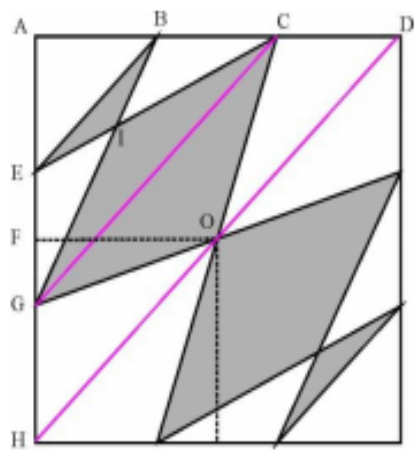
assim, a área do triângulo CGO é $10-2 \times 3=4$, pela simetria da figura. Falta calcular as áreas dos triângulos $\mathrm{BEI}$ e IGC, que são semelhantes.

Fonte: Gabarito e resolução indicado no banco de provas da Obmep, 2016.

Situação de institucionalização: mais uma vez recorremos ao pensamento de Brousseau (1986, p. 343), quando explica: "a etapa final que coloca o conceito sob o controle de uma teoria matemática, permite defini-lo, exatamente, por meio de estruturas, aonde o mesmo intervém, e as propriedades que a mesma satisfaz. Esta única etapa Ihe concede o estatuto de conceito matemático" (BROUSSEAU, 2010, p. 11). Isso posto, 
o professor atuará, de modo definitivo, para que o grupo de estudantes compreenda os conceitos matemáticos científicos de interesse e da teoria matemática formal que os governa, como consequência do jogo formal e da eleição de uma estratégia vitoriosa.

Vale comparar as construções estáticas propostas e exibidas nas figuras anteriores que envolvem algumas estratégias resumidas previstas pelo gabarito oficial e predição dos argumentos considerados no âmbito da competição oficial. Por outro lado, o professor deverá permanecer vigilante, no sentido de que muitos conhecimentos de ordem localizada, tácita e intuitiva, podem ser produzidos nas fases predecessoras, e todo o conhecimento elaborado, a partir da interação com o modelo computacional, deverá ser confrontado com os conhecimentos matemáticos formais empregados.

Almouloud (2007, p. 40) esclarece: "uma vez construído e validado, o novo conhecimento vai fazer parte do patrimônio da classe embora não tenha ainda o estatuto de saber social". Desse modo, tendo em vista tornar oficial determinado saber e indicar a relevância de incorporá-lo ao patrimônio cultural da classe, o professor deflagrará o final da SDO por intermédio da comunicação para o grupo sobre a real natureza da situação-problema. Nosso segundo caso foi o objeto abordado nas Olimpíadas Brasileiras de Matemática das Escolas Públicas, na segunda fase, em 2014.

Envolvendo outro conteúdo de Geometria Plana, podemos divisar o interesse específico da questão em determinar a área da região cinza em termos dos números arbitrários quaisquer, que representam as áreas dos quadrados a seguir indicados por $A B C D$ e EFGC. Chamamos a atenção que o uso do software GeoGebra concorrerá para a descrição e explicitação de propriedades não evidenciadas no enunciado original.

Figura 7 - Exemplo de um Problema Olímpico - PO - abordado na Obmep no ano de 2014

5. Na figura ao lado, $A B C D$ e $E F G C$ são quadrados de áreas $R$ e $S$, respectivamente. Qual é a área da região cinza?
A) $\frac{R+S}{2}$
B) $\frac{R-S}{2}$
C) $\frac{R S}{2}$
D) $\sqrt{R S}$
E) $\sqrt{R^{2}+S^{2}}$

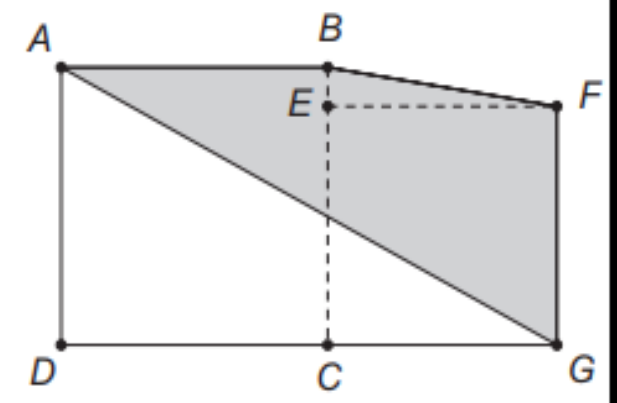

Fonte: Obmep, 2014, primeira fase, nível 3. 
Situação de ação: com amparo na visualização, os estudantes podem explorar a construção produzida com o software GeoGebra e, a partir das propriedades dinâmicas com o software, os mesmos podem correlacionar o comportamento numérico com 0 comportamento geométrico, sobretudo das expressões algébricas do tipo: (A) $\frac{R+S}{2}$; (B) $\frac{R-S}{2}$; (C) $\frac{R \cdot S}{2}$; (D) $\sqrt{R \cdot S}$; (E) $\sqrt{R^{2}+S^{2}}$.

De modo geral, o professor de Matemática deverá suscitar a atividade de interação e a produção ativa de conjecturas, direcionadas e oriundas da exploração das propriedades divisadas preliminarmente na Figura 7. Reparemos que o raciocínio explorado na fase atual possui natureza não inferencial (ver Tabela 1).

Situação de formulação: com origem nas informações coligidas na fase anterior, estimuladas pelo professor, com ênfase na visualização e entendimento das relações de natureza geométrica, algébrica e geométrica, o grupo de estudantes deverá eleger uma estratégia optimal. Nesse caso, podem determinar que o lado do quadrado maior será determinado pela seguinte expressão $\sqrt{R}$, enquanto o lado do quadrado menor é designado por $\sqrt{S}$. Logo em seguida, o segmento $\overline{B G}$ considerado na Figura 8, determinará dois triângulos respectivos $\triangle A B G$ e $\triangle B F G$.

Agora, a partir da exploração da construção a seguir, os estudantes poderão compreender que a soma das áreas dos triângulos indicados possuem a propriedade $A R E A(\triangle A B G)+A^{\prime} R E A(\triangle B F G)=A ́ R E A(A B G F)$ (ver Figura 8) e deve determinar a área da região pretendida. Na Figura 8 , ao lado esquerdo, indicamos os triângulos $A R E A(\triangle A B G)$ na cor rosa e o triângulo $A ́ R E A(\triangle B F G)$ na cor amarela.

Figura 8 - Exemplo da construção com o software, correspondente do PO, originalmente abordado nas provas de Olimpíadas e descrito segundo uma SDO

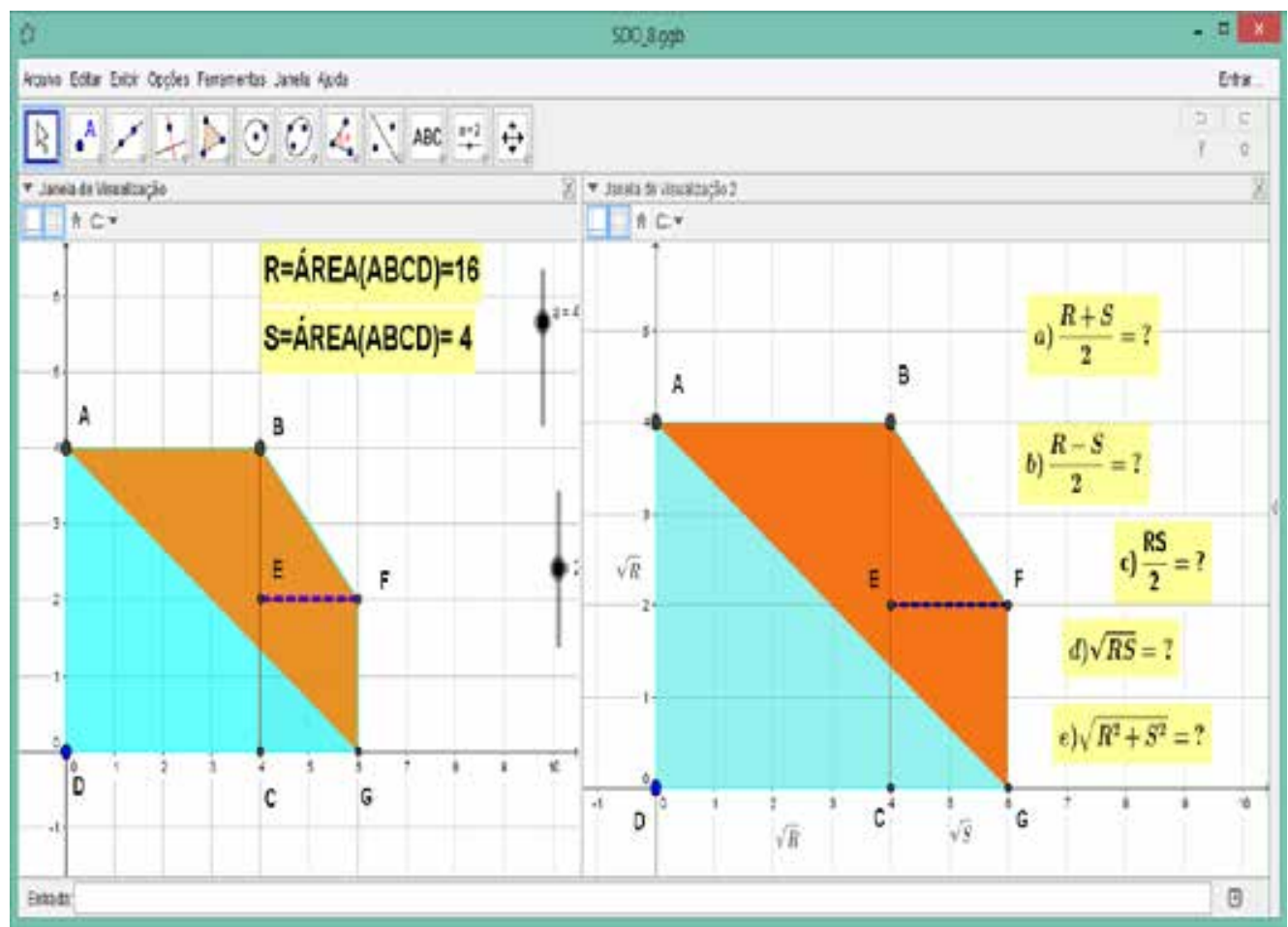

Fonte: Elaboração do autor. 
Os estudantes podem agora comparar as constrições exibidas nas Figuras 6, 7 e 8. Nas Figuras 8 e 9 exibimos uma Tabela numérica que expressa as variações possíveis para cada variação correspondente dos seletores que equivalem aos comprimentos dos lados de cada quadrado e que podem ser manipulados e determinar os valores (A) $R+S / 2=3$; (B) $R-S / 2=1$; (C) $R \cdot S / 2=4$; (D) $\sqrt{R \cdot S}=2.83$; (E) $\sqrt{R^{2}+S^{2}}=4.47$, como podemos visualizar logo em seguida e comparar com o enunciado original (ver Figura 6 ).

Figura 9 - Exemplo da construção com o software, correspondente do PO, originalmente abordado nas provas de Olimpíadas e descrito segundo uma SDO

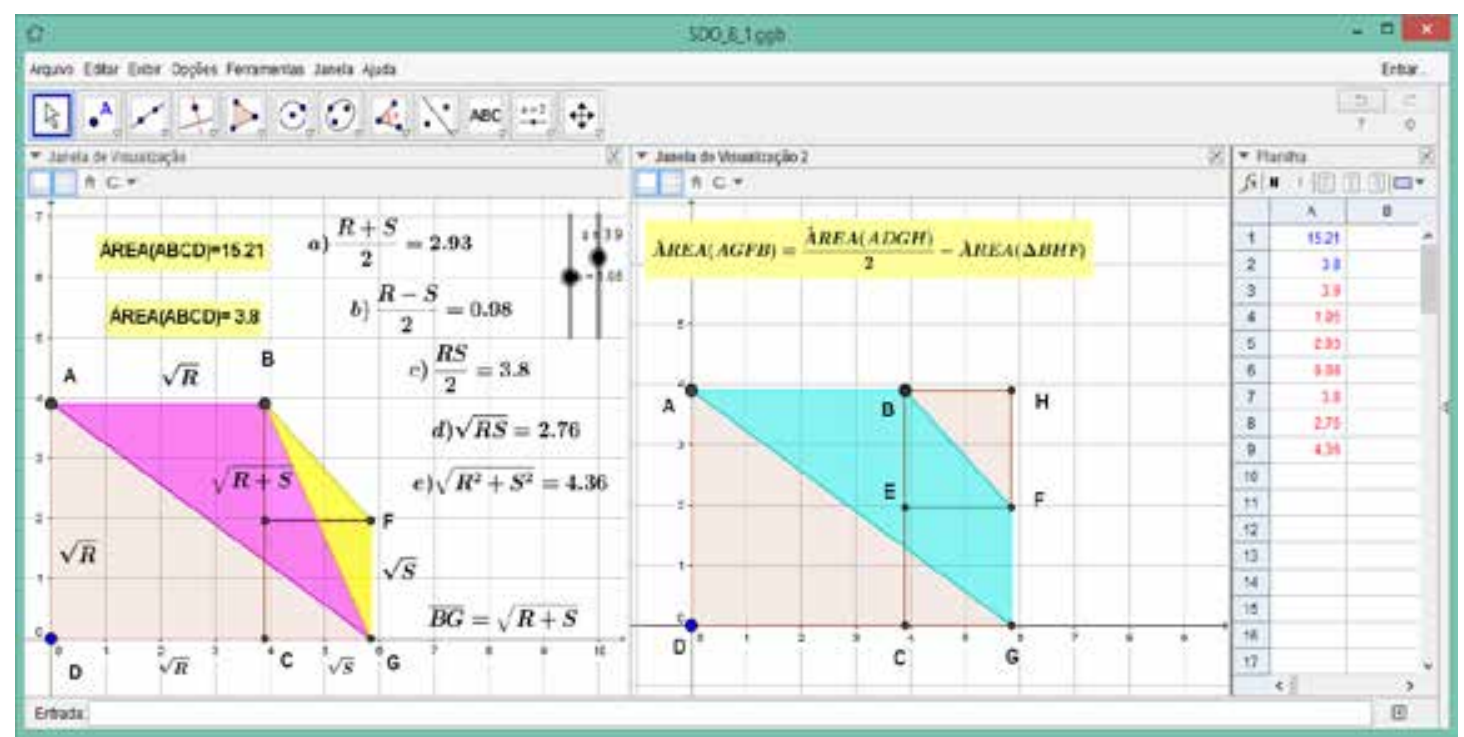

Fonte: Elaboração do autor.

Situação de validação: em consonância com o que registramos nas respostas previstas no instrumento aplicado na Obmep, desde que as asserções carecem ser confirmadas na fase atual, os estudantes podem tomar conhecimento, de modo excepcional, de que a natureza do PO abordado diz respeito ao caráter de competição oficial. Assim, o professor pode fornecer as informações que divisamos na Figura 10. Nela, eles devem encontrar suas propostas de solução da questão. $O$ teor de interesse aqui reside no fato da primeira solução proposta, a despeito de figurar com a escolha do item correto e da expressão (A) $\frac{R+S}{2}$. Nesta fase, os estudantes confrontam as informações das figuras 6 , 7, 8, 9 e 10. O modelo computacional deverá ser confrontado com o modelo axiomático, visando à fase final de institucionalização da SDO. 
Figura 10 - Exemplo da construção com o software, correspondente do PO, originalmente abordado nas provas de Olimpíadas e descrito segundo uma SDO

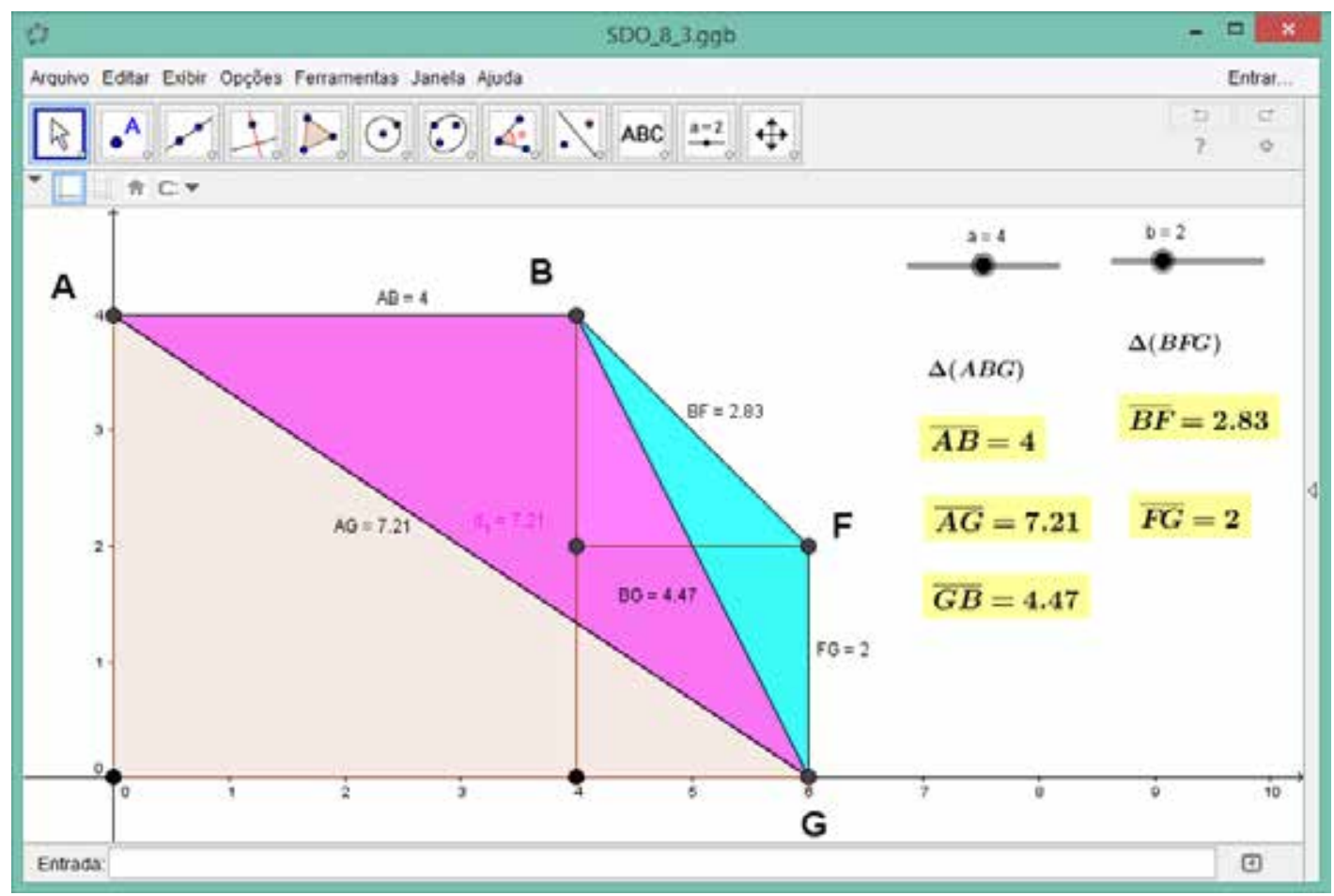

Fonte: Elaboração do autor.

Figura 11 - Estratégias previstas na prova das Olimpíadas concernentes ao gabarito

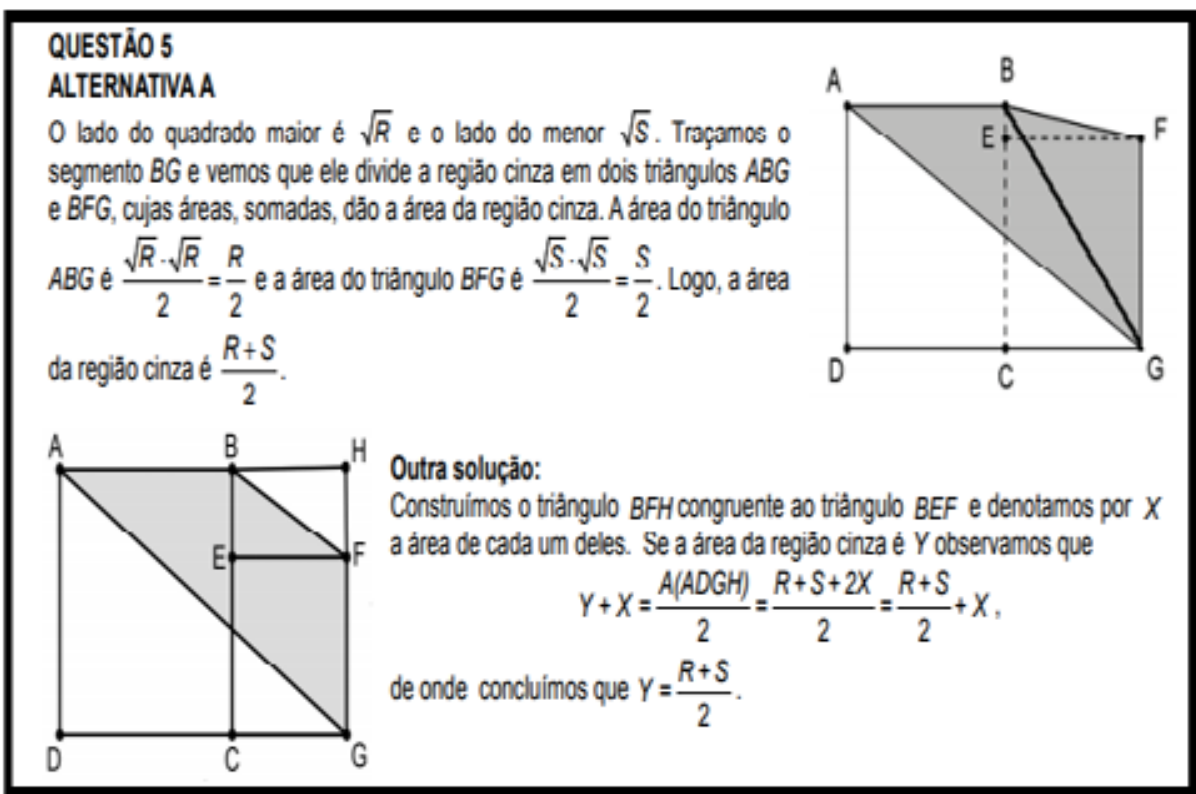

Fonte: Prova da Obmep, 2014.

Situação de institucionalização: como assinalamos na primeira SDO discutida há pouco, acentuamos a importância de proporcionar ao grupo, ou grupos de estudantes, o debate científico e o cotejo dos resultados finais coligidos em uma Situação Didática Olímpica. Na Figura 12 trazemos duas imagens da videoaula envolvendo os argumentos 
principais referentes à segunda solução indicada para a presente SDO. Retomando as ideias apresentadas e confrontadas na situação de validação, o professor deverá conduzir ao entendimento da existência eventual ou não de um "erro" previsto no gabarito/ solução de uma prova de competição olímpica. As estratégias não exitosas podem ser resgatadas e rediscutidas com o grupo na fase final de aplicação da SDO, a fim de comparar e confrontar os argumentos mobilizados na videoaula.

Ademais, as estratégias apresentadas na videoaula explicativa da solução da questão anterior merecem, também, ser comparadas com as possibilidades dinâmicas oriundas do software GeoGebra. O viés e o estilo hegemonicamente formal, resumido e exageradamente coeso das ideias discutidas no vídeo (ver Figura 12), conferem um interesse destinado, preponderantemente, para um público diminuto e reduzido de estudantes participantes do torneio, nomeadamente os estudantes competidores e inscritos oficialmente no certame.

Aqui, temos um clássico exemplo de que a mediação do professor, alterada e afetada pelas concepções e as características aqui enfatizadas (ver Tabelas 1 e 2), deverá indicar uma mediação que se diferencia das intenções pedagógicas que podemos apreciar no conteúdo a seguir exposto. De fato, o caráter de coesão e economia de argumentos podem ser comparados tanto no gabarito oficial proposto quanto no expediente empregado pelo(a) professor(a), que se apresenta como responsável pela explicação oficial no vídeo (ver Figura 12).

Figura 12 - Videoaula explicativa envolvendo algumas ideias centrais na resolução simplificada e prevista do PO original

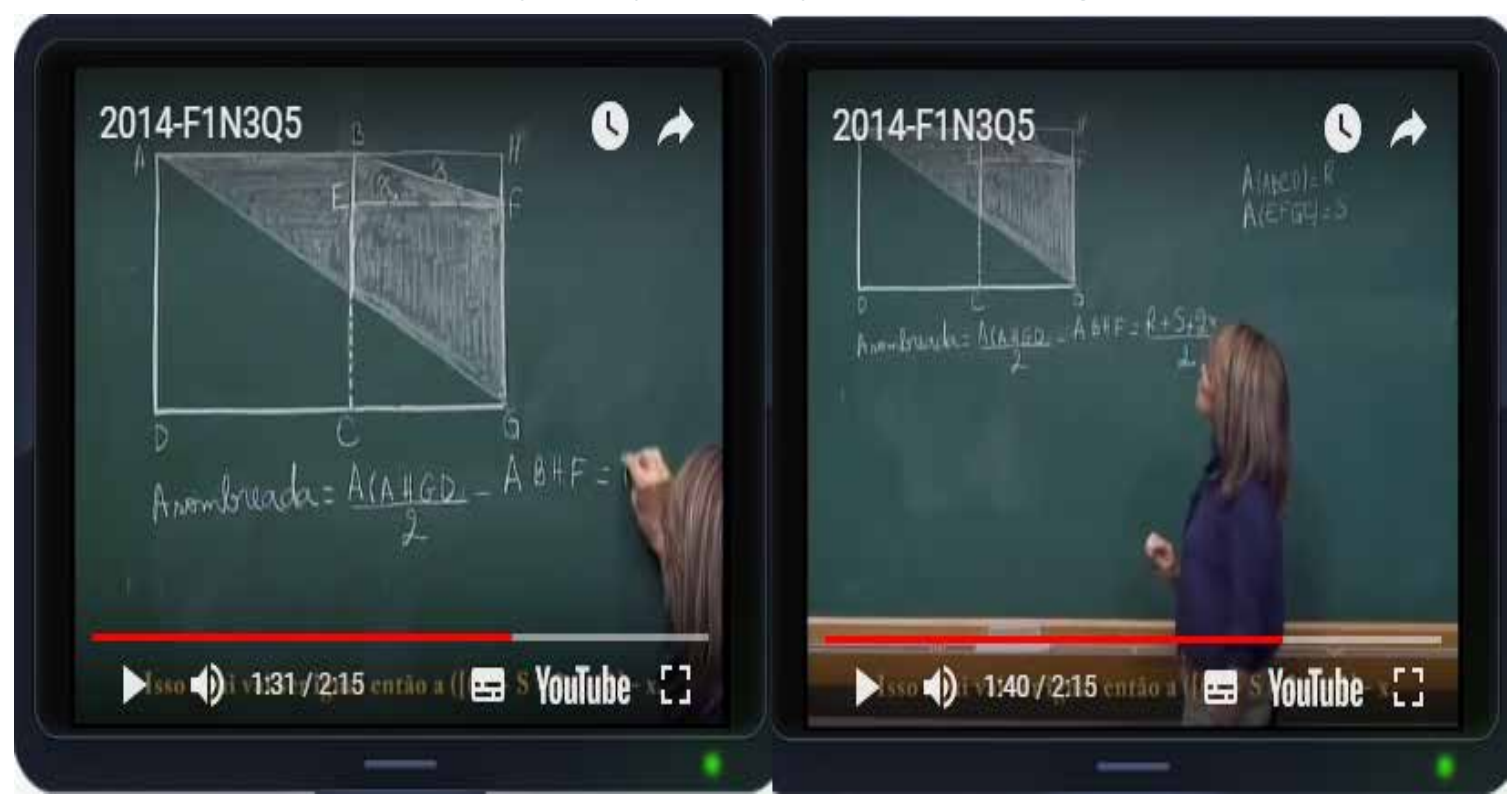

Fonte: Página de informações e site da Obmep (arquivos de provas, 2014, 2016).

Finalmente indicamos, de modo primordial, uma ação e transposição didática dos conteúdos envolvidos em ambas as Situações Didáticas Olímpicas abordadas aqui, na medida em que o professor expert deverá mobilizar aspectos distintos de formas de raciocínios formais, referendados pelo modelo axiomático da Geometria Plana, bem como outras espécies de raciocínios (ver Tabela 1), estimulados pela produção de con- 
jecturas e heurísticas primárias e locais, impulsionados pelo debate científico do grupo e da investigação paulatina, amparada pelo modelo computacional que detém o potencial de provocar alterações substanciais na mediação do professor. Do mesmo modo, recordamos as colocações emblemáticas de Ávila (2002, p. 41), quando adverte:

Ora, todos nós sabemos que ninguém aprende Matemática por que assiste aulas, por mais que seja talentoso o professor em suas exposições. É preciso trabalhar individualmente, com muita disciplina e persistência. Daí a necessidade de levarmos nossos alunos ao trabalho individual. Eles têm de aprender a andar com as próprias pernas; aprender fazendo, do mesmo modo que aprendem a andar e andar de bicicleta. [...] (ÁVILA, 2002, p. 41).

Consequentemente, extraímos um raciocínio análogo do excerto anterior, na medida em que o professor deverá investir no aperfeiçoamento persistente do seu trabaIho individual, apreender a habilidade de identificação das produções distintas dos seus estudantes e fazê-los descobrir propriedades e teoremas repetidas vezes, a depender de contextos culturais distintos (WEIL, 1991, p. 19), tomando como referência os momentos metodológicos descritos/indicados por uma SDO.

Para concluir, assinalamos o caráter de vacuidade registrada na efetivação de propostas metodológicas e de engenharias de formação (ARTIGUE, 1984, 2003, 2009, 2012, 2013), visando o aperfeiçoamento sistemático da ação do professor direcionada, localizada e circunstanciada pelo âmbito das Olimpíadas de Matemática. Da mesma forma, o lacônico aspecto cumulativo crescente de dissertações voltadas para a discussão da prática profissional de ensino, circunstanciadas no contexto das Olimpíadas, pode permanecer, de modo superficial, na discussão academicista de uma profusão de formas resolutivas, entretanto não são acompanhadas da mudança real de uma atuação do professor no ambiente de trabalho e o correspondente estímulo de participação de uma maior quantidade de estudantes no processo (BIONDI; VASCONCELLOS; MENEZES-FILHO, 2014; CORDEIRO, 2009; FONSÊCA; MENEGUCCI; OLIVEIRA, 2015; OLIVEIRA, 2016; PASSOS; BORGES; PEREIRA, 2014; SOUZA, 2013; TODESCHINI, 2012; VICTOR, 2013). Nas circunstâncias aqui propostas, em consonância com a própria evolução da Matemática, impulsionada pelo processo primordial solucionador de problemas (RASSIAS, 2011; SCHOENFELD, 1985), o grupo de estudantes participante poderá adquirir uma percepção positiva da Matemática.

\section{CONSIDERAÇÕES FINAIS}

O contexto de ensino de Matemática dedicado e direcionado para a competição em Ciências, de um modo geral, tende a envidar os esforços de divulgação de uma cultura matemática distinguida de sua popularização científica e da divulgação e informação em Ciências, que se consubstancia como um componente imprescindível para o cidadão em geral e, de modo especial, da percepção dos estudantes competidores e participantes, de modo direto, das maratonas e das competições em seus diversos níveis e formatos de apresentação no contexto nacional e, também, no internacional.

Nas seções antecessoras discutimos a participação, todavia, de um outro grupo de estudantes que necessita e que precisa, de modo irremediável, ser colocado em contato e conhecer, sobretudo, o estilo, as características, os elementos matemáticos substan- 
ciais, intrinsecamente mobilizados por intermédio de Problemas Olímpicos e desafios que, como registramos, costumam ser formulados por um grupo seleto de professores de Matemática que, em maior ou em menor substância, possuem fortes ligações com as instituições universitárias e replicam/reproduzem alguns de seus clássicos paradigmas, reproduzindo, no contexto escolar, uma ideologia velada, que legitima a importância da Matemática e seu caráter "seletivo" e indicação prevalente de "eleitos".

Por outro lado, a partir da proposição da noção teórica de Situação Didática Olímpica - SDO - que, laconicamente, representamos ao decurso do texto por $S D O=T S D_{\text {metodologia }}+P O_{\text {problema olimpico, }}$ perspectivamos e propugnamos certo teor de ineditismo na literatura que faz aderir e cotejar os fundamentos de uma metodologia de ensino (TSD). Assim, estruturamos e descrevemos um percurso para sua mediação ou de transposição didática (CHEVALLARD, 1991) dos saberes matemáticos, em observação a hierarquização e tipos ou categorias de raciocínios (ver Tabela 1) previstos pela Teoria das Situações Didáticas - TSD -, que tende a orientar uma ação docente capaz de proporcionar e socializar, para um grupo ou grupo de estudantes, como alternativa ao método de abordagem (ÁVILA, 2002, p. 43), uma cultura matemática originalmente veiculada pelas Olimpíadas de Matemática.

Isso posto, apontamos, nas duas situações didáticas olímpicas discutidas anteriormente, o emprego irremediável da tecnologia e a promoção da visualização e, em nosso caso, exploramos o software GeoGebra a fim de alterar/modificar o ritmo, o estilo, as caraterísticas dos raciocínios requeridos nos problemas (ver Tabela 1) e conhecimentos mobilizados em cada fase, nominadas por: situação de ação, formulação, validação e institucionalização (ver Tabela 2).

De fato, com o amparo das duas tabelas simplificadas (ver Tabelas 1 e 2) nas seções aqui discutidas, poderemos prever e descrever uma mediação do professor que necessita se apropriar de um estilo de problemas que, em certos casos, muito se destoa da Matemática oficial, corporificada nos currículos, determinada pelas instituições de ensino e direcionada para uma população maior e ampliada de estudantes (não competidores) (ALVES, 2019, 2020).

Por outro lado, não podemos nos furtar de desenvolver uma apreciação de um conjunto de dissertações oriundas da formação de professores proporcionada pelos Mestrados profissionais em Matemática Pura, em rede, e constatar que a tônica geral de muitos trabalhos tende a replicar/reproduzir e/ou propor a discussão pormenorizada de situações Problemas Olímpicos = POs de Matemática que, indubitavelmente, revelam um nível de matemática satisfatório e preciso, entretanto completamente desprovidos de uma preocupação com a inserção efetiva correspondente ao emprego da tecnologia. Do mesmo modo, ainda não temos elementos suficientes que possam garantir ou predizer que, a despeito dos professores egressos desses Mestrados profissionais, sua prática pedagógica e a sua transposição didática em sala de aula foram essencialmente modificadas/alteradas.

Por fim, a despeito do entendimento da existência de uma grande quantidade de estudantes que não manifestam interesse direto pelo estilo desafiador e competitivo, os mesmos precisam conhecer e tomar contato com o viés de uma Matemática vei- 
culada pelas Olimpíadas e que, em seus interesses primários, remonta exatamente ao pensamento histórico de grandes matemáticos do passado, diante de desafios que se descortinavam ante problemas instigantes e motivadores do intelecto.

\section{AGRADECIMENTOS}

Agradecemos o suporte financeiro no Brasil concedido pelo Conselho Nacional de Desenvolvimento Científico e Tecnológico - CNPq.

\section{REFERÊNCIAS}

ACZEL, Amir. D. Fermat's last theorem: unlocking the secret and and ancient mathematical problem. New York: Delta Book 1996.

ALMOULOUD, Ag. S. Fundamentos da didática da matemática. Paraná: UFPR. 2007.

ALVES, F. R. V. Insight: descrição e possibilidades de seu uso no ensino do cálculo. Revista VYDIA, v. 32, n. 2, p. 149-161, jul./dez. 2012. Disponível em: https://www.periodicos.unifra.br/index.php/VIDYA/article/ view/279.

ALVES, F. R. V. Didática da matemática: seus pressupostos de ordem epistemológica, metodológica e cognitiva. Revista Interfaces da Educação, v. 7, n. 21, p. 31-150, 2016.

ALVES, F. R. V. Visualizing the olympic didactic situation (ODS): teaching mathematics with support of the geogebra software. Acta Didactica Naposcencia, v. 12, n. 2, p. 97-116, 2019.

ALVES, F. R. V. Situações didáticas olímpicas (SDOs): ensino de olimpíadas de matemática com arrimo no software Geogebra como recurso na visualização. Revista Alexandria, v. 13, n. 1, p. 319-349, 2020.

ALVES, W. J. S. O impacto da olimpíada de matemática em alunos da escola pública. 2010. 30 f. Dissertação (Mestrado Profissional em Ensino de Matemática) -Pontifícia Universidade Católica de São Paulo, São Paulo. Disponível em: http://www.pucsp.br/sites/default/files/download/posgraduacao/programas/ educacaomatematica/washington_alves.pdf.

ANDRADE, F. P. As olimpíadas de matemática ampliando e fortalecendo o processo de ensino-aprendizagem. 2015. Dissertação (Mestrado Profissional em Ensino de Matemática) - Mossoró: UFRN, 2015.

ARTIGUE, Michelle. Modélisation et Reproductibilité en Didactiques de Mathématiques. Les Cahiers Rouge des Didactiques des Mathematiques, v. 8, n. 1, p. 1-38, 1984.

ARTIGUE, Michelle. Qué se Puede Aprender de la Investigación Educativa en el Nível Universitário? Boletín de La Asociation Venezolana, v. X, n. 2, p. 117-134, 2003.

ARTIGUE, Michelle. Didactical design in mathematics education. In: WINSLOW, C. (ed.). Nordic Research in Mathematics Education. Proceedings from NORMA08, p. 7-16, 2009. Rotterdam: Sense Publishers, 2009. Disponível em: https://isis.ku.dk/kurser/blob.aspx?feltid=212293.

ARTIGUE, M. L'impact curriculaire des technologies sur l'éducation mathématique. Revista de Educação Matemática e Tecnologia Iberoamericana, v. 4, n. 1, 1-4, 2013.

ARTIGUE, M. L'éducation mathématique comme champ de recherche et champ de pratique: résultats et défis. Revista de Educação Matemática e Tecnologia Iberoamericana, v. 3, n. 3, p. 1-20, 2012.

ÁVILA. G. O provão e o ensino de Matemática. Revista Matemática Universitária, n. 32, p. 39-48, jun. 2002. Disponível em: http://rmu.sbm.org.br/Conteudo/n32/n32_Artigo03.pdf.

BADARÓ, R. L. Do zero as medalhas: orientações aos professores de cursos preparatórios para Olimpíadas de Matemática. 2015. Dissertação (Mestrado Profissional) - Ufba, Salvador, 2015. Disponível em: http:// w3.impa.br/ tertu/archives/Dissertacao_Badaro.pdf.

BIONDI, R. L.; VASCONCELLOS, L.; MENEZES-FILHO, N. A. Avaliando o impacto da Olimpíada Brasileira de Matemática das Escolas Públicas (OBMEP) no desempenho de matemática nas avaliações educacionais. São Paulo: Fundação Getúlio Vargas; Escola de Economia de São Paulo, 2014.

BROUSSEAU, G. Théorisation des phénomènes d'enseignement des mathématiques. 1986. Thése (Doctorat d'Etat) - Université Bourdeux I, 1986.

BROUSSEAU, G. La théorie des situations didactiques. Cours donné lors de l'attribution à Guy Brousseau du titre de Docteur Honoris Causa de l'Université de Montréal, 1997.

BROUSSEAU, G. Glossaire de quelques concepts de la théorie des situations didactiques en mathématiques, 2010. 
BROUSSEAU, G. La théorie des situations didactiques en mathématiques. Éducation \& Didactique, v. 5, n. 1, p. 1-6, 2011.

BROUSSEAU. G.; GIBEL, P. Didactical handling of students' reasoning processes in problem solving situations. In: LABORDE, C. et al. Beyond the apparent banality of the mathematics classroom. New York: Springer, 2005. p. 3-58.

CARVALHO, M. M. Resolução de problemas de olimpíadas usando trigonometria. 2013. Dissertação (Mestrado Profissional em Matemática em Rede Nacional) - Universidade Federal do Vale do São Francisco, Juazeiro, 2013. Disponível em: http://portais.univasf.edu.br/profmat/dissertacoes/marcilio_miranda_ de_carvalho_turma_2011.pdf.

CHAN, lana. Matemáticos de ouro: o Brasil que se destaca nas olimpíadas internacionais. Revista Matemática Universitária, n. 43, p. 84-72, 2007. Disponível em: http://rmu.sbm.org.br/Conteudo/n43/n43_ Artigo04.pdf.

CHEVALLARD. Y. Sur l'ingénierie didactique. Présenté à Seconde Ecole d'été de Didactique des Mathématiques (5-17 juillet), Olivet, 1982. Disponível em: http://yves.chevallard.free.fr/spip/spip/article.php3?id_ article $=195$.

CHEVALLARD. Y. La Transposition Didactique. Paris: La Pensée Sauvage Édition. 1991.

COCCO, E. M. Olimpíada de matemática das escolas públicas e avaliação em larga escala: possíveis interlocuções. 2013. 161 fls. Dissertação (Mestrado em Educação) - Universidade Regional Integrada do Alto Uruguai e das Missões - URI, Frederico Westphalen. Disponível em: http://www.fw.uri.br/NewArquivos/ pos/dissertacao/5.pdf.

CORDEIRO, C. C. Análise e classificação de erros de questões de geometria plana da olimpíada brasileira de matemática das escolas públicas. 2009. Dissertação (Mestrado Profissional) - Unigranrio, Rio de Janeiro, 2009. Disponível em: http://tede.unigranrio.edu.br/handle/tede/18\#preview-link0.

DA SILVA, C. G. Resolução de problemas sobre geometria para as Olimpíadas Brasileira de Matemática das Escolas Públicas - OBMEP. 2013. Dissertação (Mestrado) - Universidade Federal do Pará, Belém, 2013.

DORRIE, Heinrich. 100 Great problems of elementary mathematics. New York: Dover Publications, 1965. DOUADY, R. Jeux de cadres et dialectique outil objet. Recherches en didactique des mathématiques, 7/2, 5-31, 1984.

DOUADY, R. Ingénierie didactique et évolution du rapport au savoir. Repères-IREM, $\mathrm{n}^{\circ}$ 15, 37-61, 1995.

DUARTE, A. R. S.; GALVÃO, M. E. L. Olimpíada paulista de matemática: quase quatro décadas de incentivo ao estudo da matemática. Revue Brésilienne de l'Histoire de Mathematiques, v. 14, n. 29, p. 129-143, 2014.

FEITOSA, O. L. Algumas técnicas de resolução de problemas de mínimos e máximos na Geometria. 2015. Dissertação (Mestrado Profissional) - Universidade Federal de Roraima, Boa Vista, 2015. Disponível em: http://www.bdtd.ufr.br/tde_arquivos/7/TDE-2015-06-19T090151Z-236/Publico/OsmilcyLimaFeitosa.pdf FONSÊCA, K. F.; MENEGUCCI, U. E.; OLIVEIRA. F. M. Análise das provas da olimpíada brasileira de matemática das escolas públicas. LINKSCIENCEPLACE - Interdisciplinary Scientific Journal, v. 4, n. 3, p. 6387, 2015. Disponível em: http://revista.srvroot.com/linkscienceplace/index.php/linkscienceplace/article/ view/95/39.

KENDEROV, P. Competitions and Mathematics Education. Proceedings of the International Congress of Mathematicians. Madrid, 2006. p. 1.583-1.598. Disponível em: http://icm2006.mathunion.org/proceedings/Vol_III/contents/ICM_Vol_3_76.pdf.

KENDEROV, P. World Federation of National Mathematics Competitions. A Short History. Mathematics Competitions, 22(2), p. 14-31, 2009. Disponível em: http://www.wfnmc.org/history.pdf.

KENDEROV. P. et al. Challenges Beyond the Classroom - Sources and Organizational Issues. In: Challenging Mathematics In and Beyond the Classroom. The 16th ICMI Study. New York: Springer, 2011. p. 53-97.

KOSHY, T. Pell and Pell Lucas numbers with applications. New York: Springer Verlag, 2014.

KRANTZ, Steven. G. An Episodic History of Mathematics: Mathematical Culture through Problem Solving. Washington: Mathematical Association of America, 2000.

LOSADA. M. F. et al. Curriculum and Assessment that Provide Challenge in Mathematics. In: Challenging Mathematics In and Beyond the Classroom. The 16th ICMI Study. New York: Springer, 2011. p. 243-285, 2011.

MARGOLINAS, C.; DRIJVERS, P. Didactical engineering in France; an insider's and an outsider's view on its foundations, its practice and its impact. ZDM Mathematics Education. p. 893-903, 2015. 
MARTINS. R. A. Colinearidade e concorrência em olimpíadas internacionais de matemática: uma reflexão voltada para o ensino da Geometria Plana no Brasil. 2015. Dissertação (Mestrado) - ProfMat: Brasília. Disponível em: http://repositorio.unb.br/bitstream/10482/19191/1/2015_RonaldAlexandreMartins.pdf. MOLCHANOV, E. B. D.; TOLPYGO , A. K. Mathematical problems: an anthology. New York:, Gordon \& Breach; New York Publishers, 1969.

OBMEP: banco de questões 2014. Rio de Janeiro: Impa, 2014. Disponível em: http://www.obmep.org.br/ provas_static/sf1n3-2014.pdf

OBMEP: banco de questões 2016. Rio de Janeiro: Impa, 2016. Disponível em: http://www.obm.org.br/ content/uploads/2017/01/1fase_nivel1_2016-1.pdfOLIVEIRA, C. C. N. Olimpíadas de Matemática: concepção e descrição de situações olímpicas com o recurso do software Geogebra. 2016. Dissertação (Mestrado Profissional) - ProfMat, Fortaleza. Disponível em: https://www.academia.edu/30082719/Dissertacao_de_Mestrado_Cicera_Carla.

OTTE, M. O formal, o social e o subjetivo. São Paulo: Unesp, 1998.

PASSOS, E. O.; BORGES, V. V.; PEREIRA, R. M. Organização de uma olimpíada interna de matemática para quartos e quintos anos do ensino fundamental: contributo para a formação de futuros professores. $R e-$ vista de Educação e Ensino, a. XVI, n. 20, p. 103-114, 2014. Disponível em: http://www.seer.ufu.br/index. php/olharesetrilhas/article/viewFile/24939/17101.

PEREIRA, M. M. A resolução de questões das olimpíadas de matemática com teoremas da aritmética. 2016. Dissertação (Mestrado Profissional) - Profmat, Universidade Federal de Rondônia, Porto Velho. Disponível em: http://www.ri.unir.br/jspui/bitstream/123456789/1608/1/Disserta\%C3\%A7\%C3\%A3o-Maily\%20Marques\%20Pereira\%20final1.pdf.

PRASAD, P. Mathematics Olympiads in Indian. Azim Premji University At Right Angles, p. 85-91, nov. 2018. Disponível em: https://azimpremjiuniversity.edu.in/SitePages/pdf/Publications/At-Right-Angles/Sub-PDFs/At-Right-Angles-Vol-7-No-3-november-2018/17_Phoolan_MathsOlympiadsIndia.pdf.

PROTASOV, V. et al. Challenging Problems: Mathematical Contents and Sources. In: Challenging Mathematics In and Beyond the Classroom. The 16th ICMI Study. New York: Springer, 2011. p. 11-53.

RASSIAS, M. Th. Problem-Solving and Selected Topics in Number Theory: In the Spirit of the Mathematical Olympiads. New York: Springer, 2011.

ROGALSKI, M. Enseigner des méthodes em mathématiques. Didactiques des Mathématiques, v. 1, n. 1, p. 1-10, 1990. Disponível em: http://www.numdam.org/article/PSMIR_1989-1990 5_A1_0.pdf. Acesso em: 20 nov. 2017.

SCHOENFELD, A. H. Mathematical Problem Solving. Orlando: Academic Press Publishers, 1985.

SILVA. R. C. O estado da arte das publicações sobre as olimpíadas de ciências no Brasil. 2016. Dissertação (Mestrado) - Goiânia: Universidade Federal de Goiás. Disponível em: https://mestrado.prpg.ufg.br/ up/97/o/DISSERTA\%C3\%87\%C3\%830_COMPLETA_-_Renato_Candido_da_Silva.pdf.

SOUZA, G. L. Situações didáticas olímpicas para o ensino de funções: o contributo da engenharia didática de segunda geração. 2013. Dissertação (Mestrado Profissional). ProfMat, Belém, PA, 2013. Disponível em: http://www.ppgme.ufpa.br/Minha\%20Disserta\%C3\%A7\%C3\%A3o.pdf.

STEWART, I. Visions of Infintity: the great mathematical problems. New York: Basic Books, 2013.

TODESCHINI, I. L. Olimpíadas Brasileiras de Matemática das Escolas Públicas (OBMEP): uma visão sobre a avaliação na perspectiva da resolução de problemas. Porto Alegre: UFRGS, 2012. Disponível em: http:// www.lume.ufrgs.br/handle/10183/54862.

VICTOR, C. A. S. Olimpíada de Matemática: que preciosidades matemáticas envolvem os problemas desta competição e qual o seu impacto para o professor de matemática sem experiência em olimpíadas e a sua importância para o estudante. 2013. Dissertação (Mestrado em Rede Nacional) - Profmat, Rio de Janeiro, 2013.

WEIL, A. História da Matemática: porque e como? Revista Matemática Universitária, n. 13, p. 17-30. jun. 1991. Disponível em: http://rmu.sbm.org.br/Conteudo/n13/n13_Artigo01.pdf. 